\title{
COMPARTIMENTAÇÃO GEOMORFOMÉTRICA DA BACIA HIDROGRÁFICA DO RIO ITÚ/RS
}

\section{GEOMORPHOMETRIC COMPARTMENTATION OF RIVER BASIN ITU/RS}

\author{
Romario Trentin \\ Departamento de Geociências, Universidade Federal de Santa Maria \\ Av. Roraima, 1000, Prédio 17, Santa Maria, Rio Grande do Sul, CEP 97105-900, Brasil. \\ E-mail: romario.trentin@gmail.com
}

Luís Eduardo de Souza Robaina

Departamento de Geociências, Universidade Federal de Santa Maria Av. Roraima, 1000, Prédio 17, Santa Maria, Rio Grande do Sul, CEP 97105-900, Brasil. E-mail: lesrobaina@yahoo.com.br

\section{Claudinei Taborda da Silveira}

Departamento de Geografia, Universidade Federal do Paraná Rua Cel. Francisco Heráclito dos Santos S/N, Curitiba, Paraná, CEP:81531980, Brasil

\section{Informações sobre o Artigo}

Data de Recebimento: 14/07/2014

Data de Aprovação:

26/04/2015

\section{Palavras-chave:}

Parametrização da Morfologia; Bacia Hidrográfica do Rio Itu; Atributos Topográficos.

\section{Keywords:}

Parameterization of Morphology; River Itu Basin; Topographic Attributes

\section{Resumo:}

O presente trabalho apresenta a compartimentação geomorfométrica como uma experiência de zoneamento do relevo. Emprega quatro atributos topográficos: elevação, plano e perfil de curvatura e declividade, cujas variáveis são derivadas de um MDE. A classificação é realizada por meio do cruzamento dos atributos gerados por meio de SIG e hierarquizados por meio de uma árvore de decisão baseado em valores pré-definidos, com base em conhecimento de campo prévio da área. Foram identificadas 24 unidades, reagrupadas em 12 compartimentos geomorfométricos, que constituem as unidades mais representativas da morfologia do relevo da bacia hidrográfica do rio Itu, no estado do Rio Grande do Sul, Brasil.

\footnotetext{
Abstract:

This paper presents the geomorphometric compartmentalization as an experience of zoning relief. Employs four topographic attributes: elevation, plan and curvature and slope, whose variables are derived from an MDE profile. The classification is carried out by crossing the attributes generated by the GIS and prioritized by a Tree based on predefined values based on prior knowledge of the field area decision. Have been identified 24 units, grouped into 12 geomorphometric compartments, which are the most representative units of the morphology of the relief of river basin Itu, state of Rio Grande do Sul, Brazil.
} 


\section{Introdução}

Para introduzir a reflexão acerca das questões geomorfológicas parte-se da premissa de que o relevo - objeto de estudo da geomorfologia - é o resultado da atuação de forças tectônicas e estruturais, e pelos mecanismos morfoclimáticos ao longo do tempo geológico, podendo ocorrer de forma sucessiva ou simultânea. Essas forças são definidas como forças endógenas (dobramentos, falhamentos, vulcões) e forças exógenas (decomposição, erosão e acumulação) (Penck, 1953; Mescerjakov, 1968; Ross, 1990; Guerra e Guerra, 2005). A partir disso, as formas que o relevo apresenta são ao mesmo tempo consequências da atuação dessas forças, bem como das suas causas. Por meio das variações topográficas e morfológicas abre-se espaço para a interferência da ação da gravidade, que possibilita, por exemplo, o deslocamento de matéria e energia líquida ou sólida das partes mais altas para as mais baixas, em um processo contínuo de desgaste dos terrenos elevados e de acumulação nos segmentos mais baixos (ROSS, 1990).

Desse modo, destaca-se a importância da compartimentação do relevo, com grande potencial de emprego em distintas aplicações como estudos de planejamento e gestão territorial, zoneamento ambientais, cartografia geomorfológica, pedológica, de suscetibilidade geoambiental, dentre outras. Sob uma abordagem mais clássica, trabalhos de compartimentação do relevo empregam técnicas de fotointerpretação consorciadas com material cartográfico e atividades de levantamento de campo.

Conforme RADAMBRASIL (1986), o mapa geomorfológico é uma evolução metodológica e cartográfica que fixa, claramente, diferentes etapas com graduais e constantes avanços fundamentados em dois pontos essenciais: o aumento do nível interpretativo pelo mais apurado controle das relações imagem-terreno e a reorganização das informações conseguidas por meio de uma expressão gráfica que procura traduzir, no mapa, toda a visão global e a riqueza de detalhes fornecidas pela imagem de radar e por informes conseguidos na bibliografia e/ou no campo. Porém, devido ao avanço no campo da computação e dos sistemas de informações geográficas, é crescente o emprego na geomorfologia de técnicas quantitativas da superfície terrestre que são apoiadas na modelagem digital do terreno, designada por Wood (1996) de geomorfometria, com grande potencial de aplicação na compartimentação do relevo.

A geomorfometria é tratada aqui, sob a mesma compreensão de Pike et al. (2009), como primordialmente a caracterização e análise computacional da topografia contínua, constituindo um campo interdisciplinar que envolve a matemática, as geociências e, mais recentemente, a ciência da computação. É uma abordagem analítico-cartográfica para representar a topografia da Terra (TOBLER, 2000) apoiada em variáveis extraídas de um Modelo Digital de Elevação (MDE). Em suma pode ser definida como a ciência da análise quantitativa da superfície terrestre (PIKE, 2000).

Esse trabalho visa a compartimentação geomorfométrica apoiada em atributos quantitativos da topografia. Esses atributos que representam mensurações quantitativas das formas do relevo recebem distintas denominações na literatura, como atributos topográficos (MOORE et al., 1991 e 1993; WILSON E GALLANT, 2000) designação aqui adotada, parâmetros das formas do relevo (SPEIGHT, 1968), variáveis morfométricas (SHARY et al., 2002), variáveis geomorfométricas (MUÑOZ, 2009; BISPO et al., 2009), informações do terreno (MARTINONI, 2002), atributos do terreno (PENNOCK, 2003; CÁTEN, 2009), atributos geomorfométricos (SCHMIDT e DIKAU, 1999), atributo do relevo (IPPOLITI et al., 2005; SIRTOLI et al., 2008).

Hugget (1975) estabelece a combinação de formas de vertentes combinando a curvatura em perfil e em plano; propõe nove padrões ideais para indicações das direções dos fluxos da água sobre as vertentes, cujas diferenças nos solos e na paisagem são resultantes, em parte, do movimento da água e sua distribuição nas vertentes.

A compartimentação empregou quatro atributos topográficos: elevação, declividade, plano e perfil de curvatura, e se utilizou de técnica de classificação não-supervisionada de formas do relevo por meio de árvore de decisão (IWAHASHI e PIKE (2007; VASCONCELOS et al., 2012; SILVEIRA et al. 2014A). A árvore de decisão é um método de processamento que se baseia em parâmetros pré-determinados, conforme as características dos atributos e suas respectivas classes o processamento das informações vai definindo os caminhos de relações e interações entre os determinados atributos a fim de que sejam atendidos os parâmetros previamente determinados, sem qualquer manipulação e/ou interferência manual do operador. Uma árvore de decisão é uma estrutura simples em que as folhas contêm as classes, os outros nodos representam atributos baseados em testes com um ramo para cada possível saída. Para classificar um objeto, começa-se com a raiz 


\section{Compartimentação Geomorfométrica da Bacia Hidrográfica do Rio Itú/RS}

da árvore, aplica-se o teste e tomase o ramo apropriado para aquela saída. O processo continua até uma folha ser encontrada. Em tal caso garante-se que o objeto pertence à classe nomeada pela folha (RUIZ, et al., 2009).

\section{Método}

O recorte espacial utilizado é a bacia hidrográfica do rio Itu (BHRI), localizada no oeste do Rio Grande do Sul (RS), cuja área é de 2.809,61 km² (Figura 1). Optou-se pela escolha da bacia hidrográfica como unidade de análise pois constitui um sistema natural bem delimitado no espaço onde os elementos e atributos que compõem esta área atuam como sistema integrado (SANTOS, 2004).

A compartimentação geomorfométrica da BHRI segue a proposta de mapeamento geomorfométrico automatizado de Iwahashi e Pike (2007), que consiste na classificação não-supervisionada das formas do terreno utilizando uma árvore de decisões com base nos valores médios de atributos topográficos, com base em resultados experimentais de aplicações realizadas no estado do Paraná por Silveira et al. (2014a).

A classificação foi realizada por meio do cruzamento de informações e atributos topográficos gerados em SIG e hierarquizados em uma árvore de decisão, amparado em valores pré-definidos, com base em conhecimento prévio da área de estudo. Como base cartográfica para a geração do MDT foram utilizadas as cartas topográficas do exército em escala 1:50.000, sobre as quais foram extraídas as informações das curvas de nível de equidistância de 20 metros somadas aos pontos cotados presentes na área. Além disso, realizouse a interpolação destas informações altimétricas utilizando-se o interpolador ANUDEM (Hutchinson 1989, 1996, 2008), disponível como ferramenta no aplicativo ArcMap versão 10.1 (ESRI, 2013), que cria um modelo digital do terreno hidrologicamente consistentes.

Foram empregados quatro atributos topográfico: altimetria, declividade, perfil de curvatura e plano de curvatura. As operações para a geração desses atributos foram executadas por meio de janelas móveis 3x3 no MDT de estrutura GRID (Figura 2-a). Essa técnica consiste em calcular os parâmetros de uma célula central apoiado nos valores da elevação das oito células vizinhas, deslocando-se sobre a grade (Figura 2-c) onde é executada uma varredura com essa janela sobre o conjunto total de dados. O espaçamento da grade, resolução das células, representado na Figura 2-b foi adotado com $\lambda=30$ metros, em função da escala da base cartográfica utilizada.

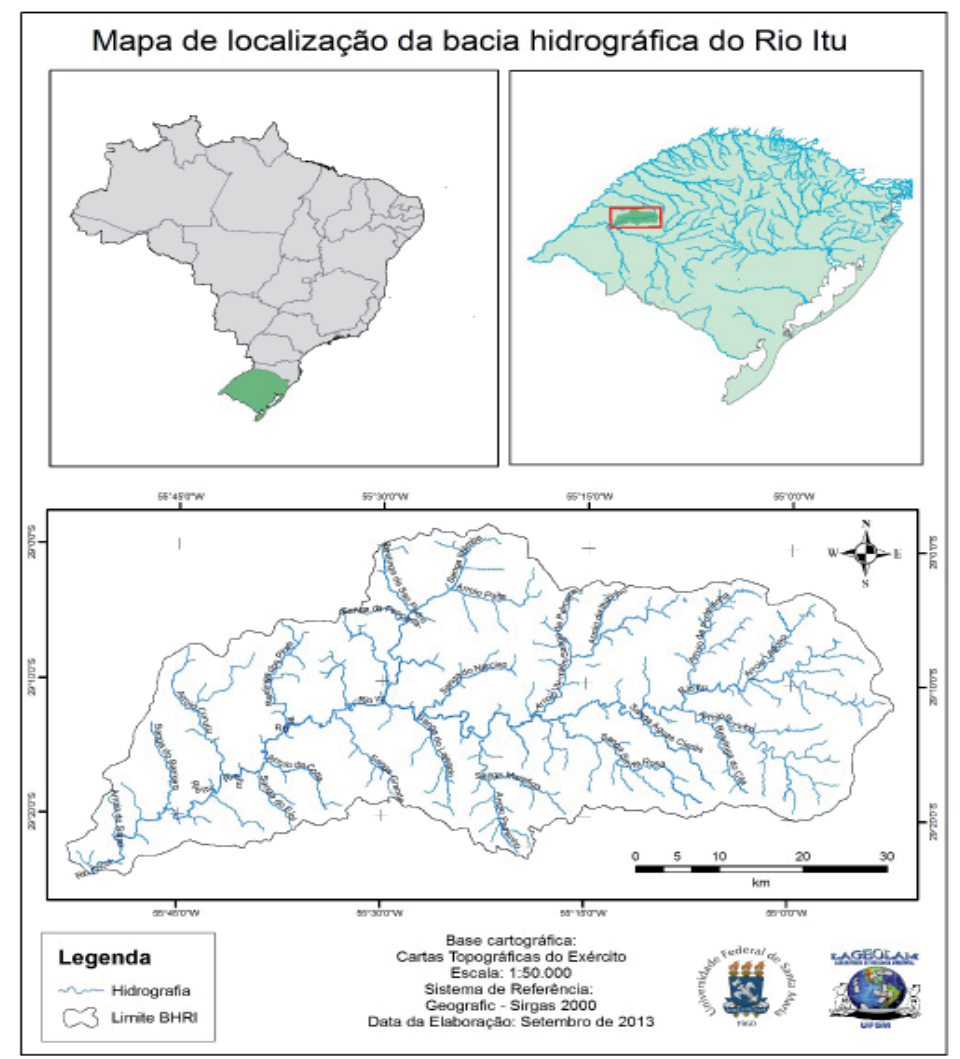

Figura 1 - Mapa de localização da bacia hidrográfica do Rio Itu. 


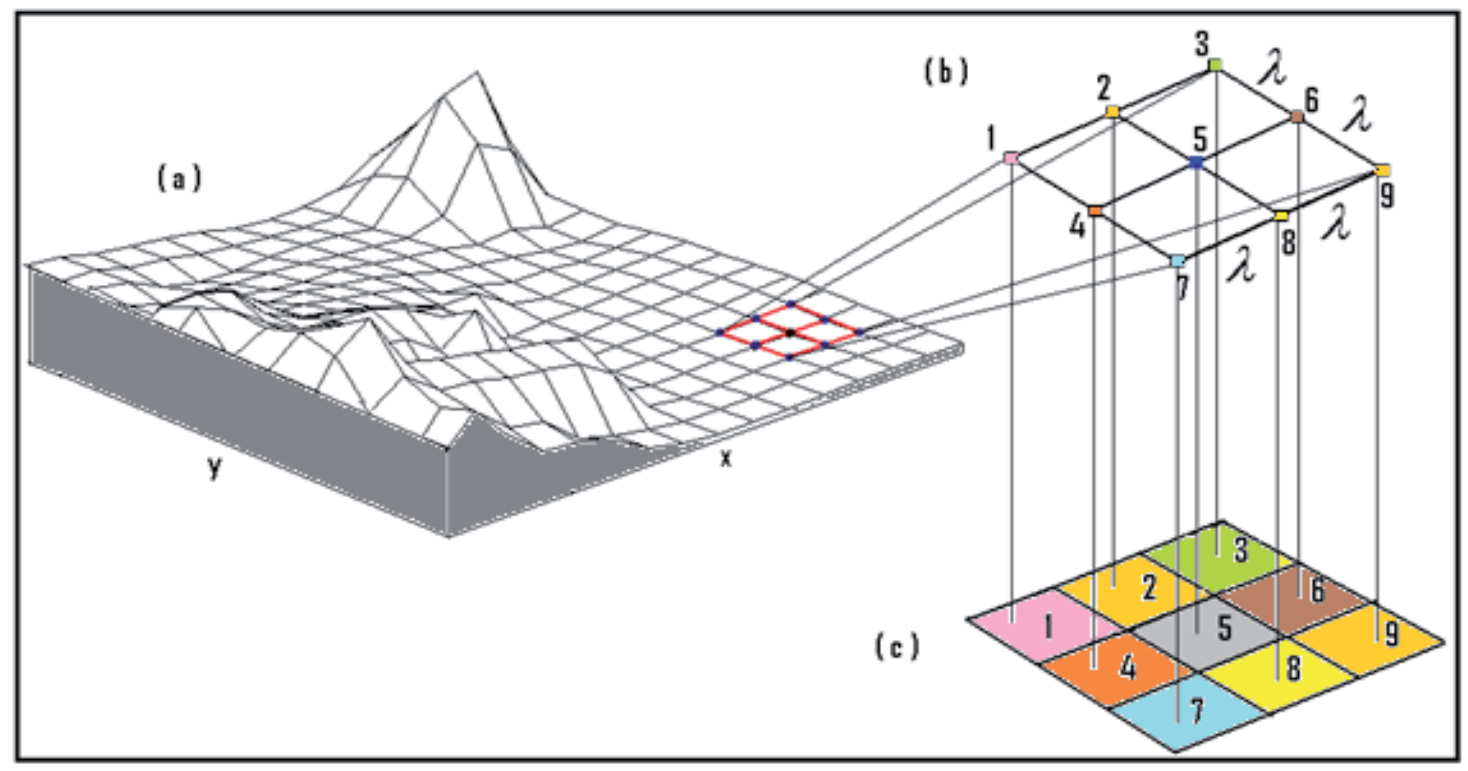

Figura 2 - Representação do MDT na estrutura GRID e janela móvel 3x3.

Fonte: Silveira et al. (2014b)

As operações sobre o MDT permitiram calcular as derivadas direcionais empregando a vizinhança local 3 x 3 representada na Figura 3, onde os valores de $Z_{i}$ são representados pela elevação, distribuída regularmente numa matriz.

\begin{tabular}{|c|c|c|}
\hline$Z_{1}$ & $Z_{2}$ & $Z_{3}$ \\
\hline$Z_{4}$ & $Z_{5}$ & $Z_{6}$ \\
\hline$Z_{7}$ & $Z_{8}$ & $Z_{9}$ \\
\hline
\end{tabular}

Figura 3 - Vizinhança local da janela móvel 3x3.

O polinômio empregado no cálculo das derivadas direcionais para a declividade foi de Horn (1981) e para o plano de curvatura foi de Zevenbergen e Thorne (1987). A opção se deve em virtude de ser o cálculo adotado na extensão do ArcGIS, do módulo Spatial Analyst (ESRI, 2010). O atributo topográfico declividade ( $\beta$ ), em valores percentuais, foi obtido conforme descrito na equação 1, cuja derivada direcional leste-oeste (G) é apresentada na equação 2 e a derivada direcional norte-sul $(\mathrm{H})$ na equação 3, de acordo com o polinômio de Horn (1981):

$$
\begin{array}{cc}
\beta=\sqrt{\left(G^{2}+H^{2}\right)} & \text { Equação 1 } \\
G=\frac{\left(Z_{3}+2 Z_{6}+Z_{9}\right)-\left(Z_{1}+2 Z_{4}+Z_{7}\right)}{8 \lambda^{2}} & \text { Equação 2 }
\end{array}
$$

$$
H=\frac{\left(Z_{1}+2 Z_{2}+Z_{3}\right)-\left(Z_{7}+2 Z_{8}+Z_{9}\right)}{8 \lambda^{2}} \quad \text { Equação } 3
$$

As variáveis Perfil de curvatura $(\varphi)$ e Plano de curvatura $(\varpi)$, expressas nas equações 4 e 5 , foram calculadas conforme as derivadas D, E, F, G e H do polinômio de Zevenbergen e Thorne (1987), respectivamente representados nas equações 6 a 10 .

$$
\begin{array}{cr}
\varphi=\frac{2\left(D G^{2}+E H^{2}-F G H\right)}{G^{2}+H^{2}} 100 & \text { Equação 4 } \\
\varpi=\frac{2\left(D H^{2}+E G^{2}-F G H\right)}{G^{2}+H^{2}} 100 & \text { Equação 5 } \\
D=\frac{\frac{\left(Z_{4}+Z_{6}\right)}{2}-Z_{5}}{\lambda^{2}} & \text { Equação 6 } \\
E=\frac{\frac{\left(Z_{2}+Z_{8}\right)}{2}-Z_{5}}{\lambda^{2}} & \text { Equação 7 } \\
F=\frac{\left(-Z_{1}+Z_{3}+Z_{7}-Z_{9}\right)}{4 \lambda^{2}} & \text { Equação 8 } \\
G=\frac{-Z_{4}+Z_{6}}{2 \lambda} & \text { Equação 9 } \\
H=\frac{Z_{2}-Z_{8}}{2 \lambda} & \text { Equação 10 }
\end{array}
$$




\section{Compartimentação Geomorfométrica da Bacia Hidrográfica do Rio Itú/RS}

Quanto as informações altimétricas empregadas, são consideradas as variações de amplitude apresentada pela bacia hidrográfica, indicando condições mais propícias a dissecação para as áreas de maior altitude e de acumulação para as áreas de menor altitude. Desta forma estas informações foram consideradas em função da distribuição do histograma de frequência, onde foi considerada a média geral das altimetrias que corresponde a 187 metros. A escolha por este valor como limite corresponde ainda a sua proximidade com uma situação de quebra natural do relevo, ou seja, a base do rebordo do planalto que nesta área apresenta as altitudes próximas a 200 metros.

As informações de declividades são informações geradas a partir do MDT e foi obtida no presente trabalho por meio do polinômio de Horn (1981). Corresponde a um dos mais importantes parâmetros na análise das vertentes, pois representa sua inclinação. Foi discretizada em duas classes cujo limite é de $5 \%$. As vertentes com altas declividades estão mais sujeitas a processos denudacionais, enquanto as de baixa são propícias aos processos agradacionais.

As vertentes podem ser definidas de forma simplificadas como um elemento da superfície terrestre inclinado em relação à horizontal, que apresenta um gradiente e uma orientação no espaço (VELOSO, 2002), e dessa forma podem ser classificadas de acordo com a sua curvatura no plano ou em perfil.

O plano de curvatura da vertente corresponde a variação do gradiente de arqueamento na direção ortogonal da vertente (curvatura da superfície perpendicular à direção da inclinação) e refere-se ao caráter divergente/ convergente do terreno, enquanto, o perfil de curvatura é a taxa de variação do gradiente de arqueamento na direção de sua orientação (a curvatura da superfície no sentido do declive) e está relacionada ao caráter convexo/côncavo do terreno sendo decisiva na aceleração ou desaceleração do fluxo da água sobre o mesmo. Ambos foram obtidos a partir do MDE por meio do emprego do polinômio de Zevenbergen e Thorne (1987).

O perfil das vertentes, em ambiente SIG, é analisada de acordo com seu valor de curvatura (histograma de frequência) e teoricamente, vertentes retilíneas têm valor de curvatura nulo, vertentes côncavas os têm positivos e convexas têm curvatura negativa (VALERIANO, 2003). Porém, vertentes com valores nulos são muito raras na natureza, assim muito pouco do que se julga retilíneo apresenta valor de curvatura realmente nulo, mas sim valores pertencentes a um intervalo de tolerância na vizinhança desse valor. No presente trabalho adotou-se o limite 0 (zero) para determinação das duas classes do perfil de curvatura, as vertentes côncavas (com valores positivos no histograma de frequência) e as vertentes convexas (com valores negativos no histograma de frequência).

A curvatura no perfil é a taxa de variação da declividade na direção do aspecto enquanto a curvatura no plano é a taxa de variação da declividade na direção ortogonal a do aspecto (MENDIONDO et al., 1998).

O perfil de curvatura é importante para caracterizar mudanças na velocidade do fluxo da água e processos relacionados ao transporte de sedimentos, enquanto que o plano de curvatura demonstra a propensão da água convergir ou divergir no terreno (GALLANT e WILSON, 2000).

Assim, o perfil de curvatura representa a forma da vertente no sentido descendente e indica a proporção de mudança do potencial do gradiente, influenciando no fluxo da água e na velocidade de processos de transporte de sedimentos

O plano de curvatura representa a medida da convergência e divergência topográfica e por isso influencia a concentração de água na paisagem (SIRTOLI et al., 2008).

A classificação do plano de curvatura das vertentes, em ambiente SIG, é analisada de acordo com o seu histograma de frequência que indica o valor da referida curvatura. Semelhante ao perfil, os valores nulos correspondem a inexistência de curvatura correspondendo a vertentes plana, já os valores positivos representam curvatura divergente e os valores negativos correspondem a curvatura convergente. Da mesma forma que para o perfil de curvatura, utilizou-se o limite 0 (zero), para a determinação das duas classes do plano de curvatura, sendo as vertentes divergentes (com valores positivos no histograma de frequência) e as vertentes convergentes (com valores negativos no histograma de frequência).

Para as análises geomorfométricas do referido trabalho, optou-se pela classificação da curvatura das vertentes quanto ao perfil em côncavas e convexas e quanto ao plano em convergentes, divergentes e planas.

Através do cruzamento das informações utilizando-se a árvore de decisão apresentada no fluxograma da Figura 4, foram inicialmente identificadas 24 unidades. 
Após análise da distribuição espacial das unidades identificadas, juntamente com as características relacionadas a forma e modelado apresentado nas referidas unidades, estas foram reagrupadas, com relação a características semelhantes quanto aos processos de dissecação e sedimentação em 12 unidades.

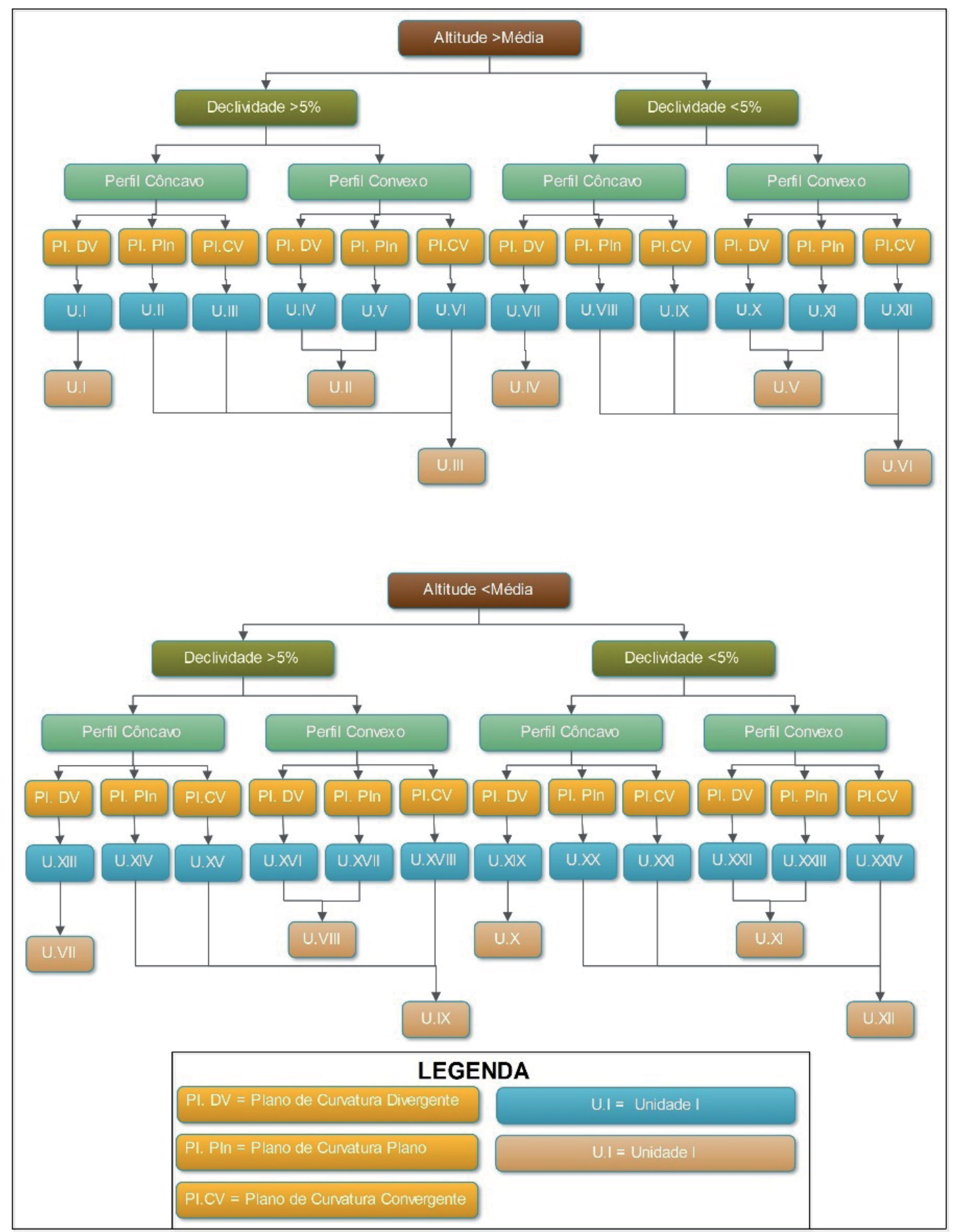

Figura 4 - Fluxograma apresentando a árvore de decisão utilizada para a definição das unidades geomorfométricas.

\section{Resultados}

Conforme Trentin (2011) a bacia hidrográfica do Rio Itu (BHRI) apresenta uma hierarquia fluvial de $7^{\text {a }}$ ordem com comprimento total dos cursos d'água de 4.834,4 km. A magnitude da bacia, ou seja, o número de nascentes, canais de $1^{\mathrm{a}}$ ordem, é de 3.266 canais. A densidade de drenagem total da bacia é de $1,72 \mathrm{~km} /$ $\mathrm{km}^{2}$. Possui uma área de $2.809,6 \mathrm{~km}^{2}$ e perímetro de $328,79 \mathrm{~km}$, apresentando o índice de circularidade é de 0,32 que representa uma bacia com baixa circularidade, 


\section{Compartimentação Geomorfométrica da Bacia Hidrográfica do Rio Itú/RS}

marcado por um forte controle estrutural. Ainda conforme Trentin (op. cit.) o canal principal apresenta-se na maior parte do seu percurso de forma encaixada, junto às linhas de franqueza do terreno que apresenta uma direção preferencial E - W. Estende-se, a partir da nascente, no sentido Leste-Oeste por $116.45 \mathrm{~km}$ até sofrer uma inflexão para o sul, seguindo até sua foz no sentido Nordeste - Sudoeste por mais $83.9 \mathrm{~km}$, onde deságua no Rio Ibicuí.

Geomorfologicamente a bacia hidrográfica do Rio Itu encontra-se inserida em dois grandes domínios morfoestruturais, a Depressão Periférica do Rio Grande do Sul e o Planalto Serra Geral, conforme define (Robaina, et al., 2010). A Depressão Periférica do Rio Grande do Sul forma uma faixa E-W no estado e representa uma área deprimida, formada pelo contato entre os terrenos de rochas sedimentares e as rochas cristalinas mais coesas. O substrato é formado por uma sequência de coberturas sedimentares da Bacia do Paraná e depósitos recentes dos rios. O Planalto Serra Geral, na bacia, aparece de forma fragmentada em duas áreas, uma a nordeste e outra a oeste e apresenta sua origem ligada ao vulcanismo que cobriu os sedimentos da Bacia do Paraná.

As províncias geomorfológicas sobre as quais a bacia hidrográfica do Rio Itu encontra-se, que são: a Depressão do Ibicuí, o Planalto das Missões e o Planalto da Campanha, (Robaina, et al., 2010). A Depressão do Ibicuí constitui a porção oeste da Depressão Periférica do RS, com processos geomorfológicos controlados pela drenagem do Rio Ibicuí e seus afluentes, atuando sobre um substrato de rochas sedimentares de diferentes tipos, com predomínio de arenitos. Nessa unidade, dominam as amplas e alongadas formas de topos convexos, regionalmente, conhecidas como coxilhas onde os processos erosivos são muito significativos.

O Planalto das Missões compreende a área desde as nascentes do Ibicuí-Mirim até as nascentes do Rio Itu. Ocorrem as áreas de maiores altitudes da bacia (ao redor de 400 metros) que correspondem aos topos regionais e pertencem aos restos de uma superfície de aplanamento. As litologias predominantes são derrames de rochas vulcânicas ácidas e básicas. Nas nascentes do Rio Toropí, ocorrem sequências sedimentares pós-vulcânicas, definidas como da Formação Tupanciretã (MENEGOTTO et al., 1968). O controle das litologias e relevos, nesta unidade, é fortemente influenciado pelos lineamentos de direção noroeste.

O Planalto da Campanha apresenta uma significativa relação com o que Chebataroff (1954, apud MÜLLER FILHO, 1970) define como Cuesta de Haedo. O planalto está representado por um relevo ondulado, com altitudes inferiores a 300 metros, a partir do baixo curso do Rio Itu e da bacia do Rio Ibirapuitã, a norte e sul do Ibicuí, respectivamente, decaindo de forma gradativa em direção a calha do Rio Uruguai.

De forma geral, o relevo da BHRI é bastante diversificado apresentando desde áreas baixas aplainadas como a planície de inundação até áreas íngremes do rebordo do planalto e áreas suavemente onduladas a onduladas no topo do planalto e médio curso da bacia hidrográfica. A menor cota altimétrica é de 60 metros, junto à planície do Rio Itu e a maior cota é de 435 metros, resultando em uma amplitude altimétrica de 375 $\mathrm{m}$. A altitude de $200 \mathrm{~m}$ marca uma transição das características de relevo na área marcado pela passagem das áreas da Depressão Periférica do RS para o Planalto.

As declividades acima de 5\% conforme IPT (1981), marcam o limite de ocorrência predominante de processos morfogenéticos erosivos. Essa informação permite a primeira divisão entre o predomínio de processos pedogenéticos e de acumulação e os processos morfogenéticos. Na BHRI a classe de declividade de 5 a $15 \%$ é a que ocupam a maior área, estendendo-se principalmente no alto e médio curso da bacia.

Quanto as características litológicas, Trentin (2011) destacar que a bacia hidrográfica do Rio Itu, apresentam um intenso controle estrutural, o que condiciona o desenvolvimento dos cursos de água, e a própria distribuição espacial dos litotipos geológicos. As litologias encontradas na área são definidas como rochas vulcânicas e sedimentares, pertencentes à Bacia do Paraná e depósitos recentes do Rio Itu. Segundo Milani (2002), a Bacia do Paraná é uma vasta região sedimentar da América do Sul, abrigando um conjunto de rochas com idade entre o Neo-Ordoviciano e o Neocretáceo. A ocorrência das rochas vulcânicas estende-se por toda a bacia hidrográfica, com exceção de duas grandes áreas no médio e baixo curso, nas quais, devido aos grandes falhamentos que causaram movimentação tectônica na área, ocorrem os arenitos fluviais da Formação Guará (TRENTIN, 2011).

Os solos da bacia hidrográfica do Rio Itu apresen- 
tam uma grande diversidade quanto aos tipos. São influenciados diretamente pela grande variação do relevo e pelas características geológicas da bacia hidrográfica que interferem na formação e diferenciação dos tipos de solos, ou mesmo, nas características de determinado solo, visto que, as rochas, material base do desenvolvimento dos solos, apresentam variação quanto as suas características de textura, estrutura e coesão frente aos processos de intemperismo. De maneira geral, junto ao relevo suavemente ondulado a ondulado, formam solos profundos, localizados principalmente no baixo e médio curso. Relevos planos em áreas junto à drenagem associam-se aos solos hidromórficos, principalmente no baixo curso, associado ao canal principal e, áreas com relevo declivoso geram solos pouco desenvolvidos, encontrados principalmente no alto curso, associados ao Rebordo do Planalto que condiciona à transição da planície para topo de Planalto.

\section{Compartimentação Geomorfometrica}

A figura 5 mostra o esquema da representação das unidades I a VI, quanto ao modelado predominante das vertentes, bem como sua ocorrência e distribuição pela bacia hidrográfica do Rio Itu.

Baseando-se nos parâmetros de altitude, declividade, plano e perfil de curvatura, foram classificados os tipos de vertentes e se estabelece o zoneamento das unidades de relevo. As figuras 6, 7, 8, 9, 10 e 11 apresentam os mapas com as Unidades geomorfométricas I à VI, respectivamente, da bacia hidrográfica do Rio Itu, que ocorrem predominantemente na porção de alto curso.

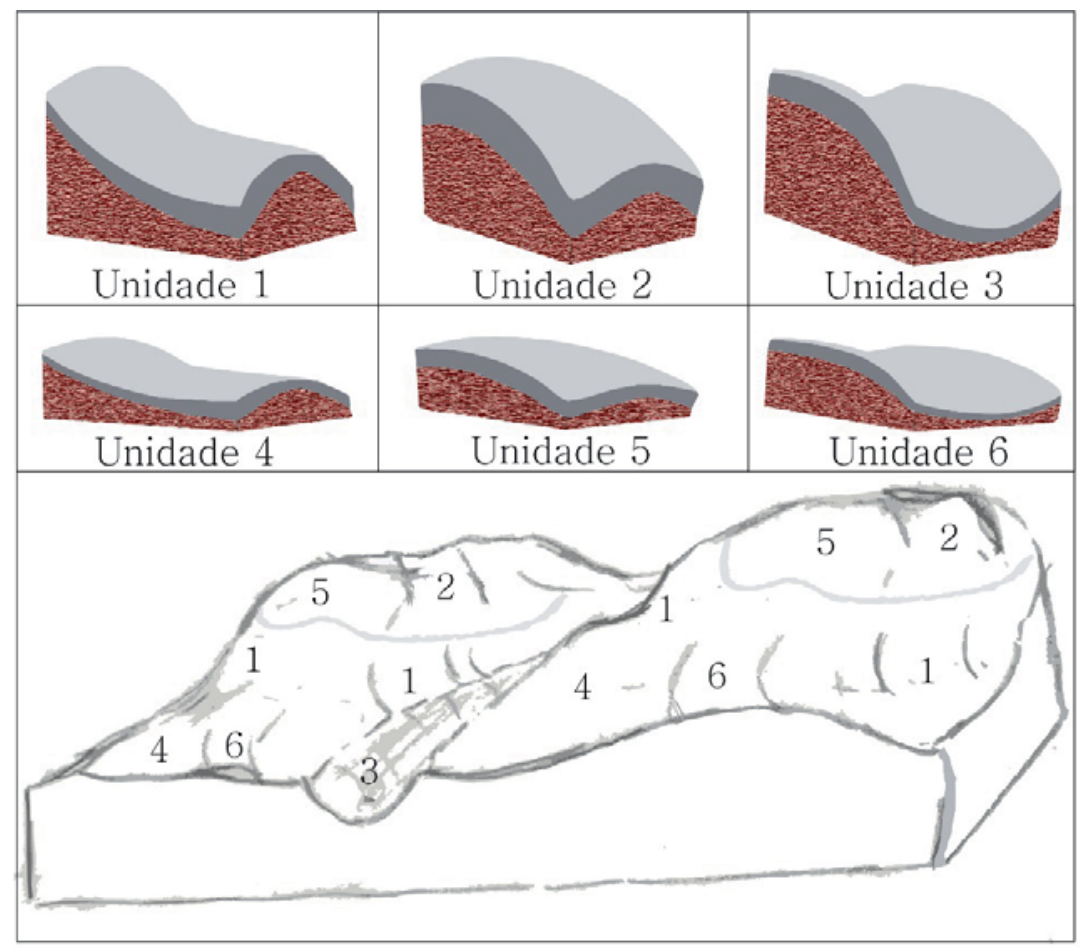

Figura 5 - Modelado e distribuição predominante das unidades I a VI.

A unidade I (Figura 6) cobre 138ha, representando quase 5\% do total da área da bacia. Está caracterizada por vertentes das áreas do alto curso da bacia, com potencialidade predominante à processos erosivos (declividade $>5 \%$ e perfil de curvatura côncavo e plano divergente). Ocorre espacialmente localizadas nas porções da meia vertente entre os vales dos canais de drenagem, principalmente nas áreas de dispersão de água.

Geomorfologicamente esta unidade encontra-se associada ao Rebordo do Planalto, à área de transição entre o Planalto das Missões e a Depressão do Ibicuí (áreas mais baixas em direção a foz da bacia). Encontra-se espacialmente distribuída sobre substrato de rochas vulcânicas, por vezes ocorrendo intercalações de arenitos intertrápicos da Formação Botucatu (TRENTIN, 2011). Com relação a inclinação geral das vertentes a pesar de apresentarem por característica padrão declividades superiores a $5 \%$, a grande maioria apresenta-se na forma escarpada, devido ao forte entalhamento dos cursos de água nas porções de Rebordo 


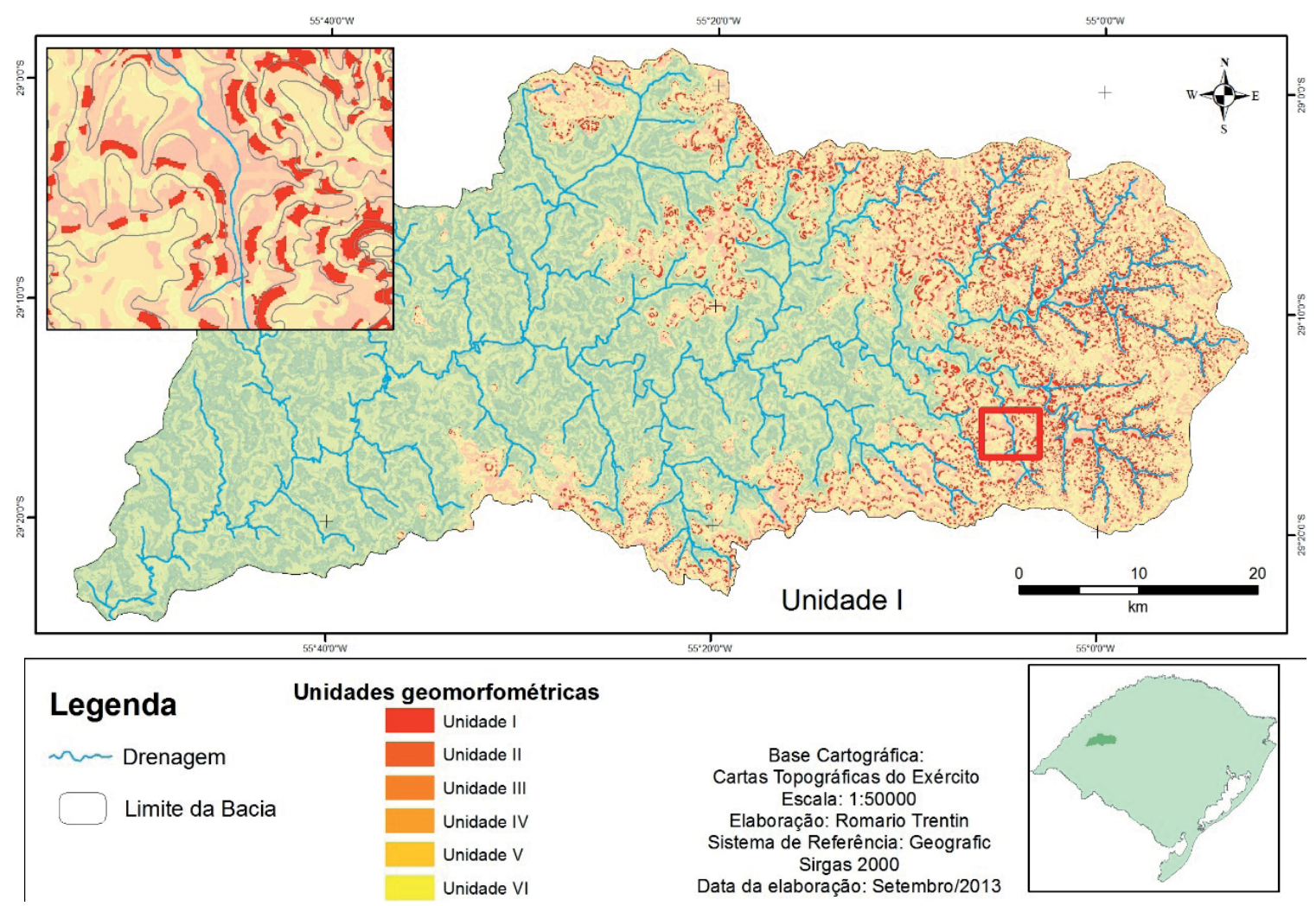

Figura 6 - Unidades geomorfométricas I.

A unidade II (Figura 7) cobre uma área de 104ha, próximo a 3,5\% da área da bacia. Representa vertentes das áreas de alto curso da bacia hidrográfica, com a velocidade de fluxo aumentando em direção a base da vertente (perfil convexo), mas com fluxo divergente (plano de curvatura divergente), o que pode gerar a formação de vários canais erosivos no terço inferior da vertente, localização espacial predominante desta unidade em função da própria declividade maior que 5\%.

Esta unidade também se estende junto ao Rebordo do Planalto, ocupando principalmente à base das vertentes, em posição predominante, associada aos canais principais. Conforme caracterização de Trentin (2011), esta unidade relaciona-se ao substrato vulcânico, porém pela sua configuração espacial na vertente, ocorre o predomínio de depósitos de tálus e colúvios, junto à base da vertente.

A unidade III (Figura 8), cobre aproximadamente 290ha, sendo 8,5\% do total da área da bacia. Localizada a montante da bacia hidrográfica (altitudes maiores que a média), com inclinações que favorecem processos erosivos (declividades superiores a 5\%). Predominam vertentes que apresentam uma diminuição da energia do fluxo em direção a base (perfil côncavo), entretanto o fluxo convergente pode ocorrer erosão concentrada que avançando a remontante. Ocorre nas porções de vertentes localizadas junto aos canais de drenagem.

Geomorgologicamente esta unidade estende-se pelas colinas de rochas vulcânicas, tendo, confome Trentin (2011), seu substrato rochoso, predominantemente rochas vulcânicas, por vezes intercalações de arenito intertrápico (Formação Botucatu). Espacialmente associam-se aos afluentes dos canais principais, por vezes apresentando-se na forma de vales encaixados.

A unidade IV (Figura 9), cobre aproximadamente 209ha, correspondendo a 7,5\% da área da bacia hidrográfica. Está representada no alto curso, formadas por áreas planas com predomínio de pedogênese sobre a morfogêne (declividades inferiores a 5\%). Os processos variam do topo para a base da vertente pela diminuição da energia do fluxo divergente (perfil côncavo e plano divergente). Ocorre associada, principalmente a unidade I nas porções mais planas, espacialmente posicionadas no terço superior da vertente. 
Trentin R. et al.

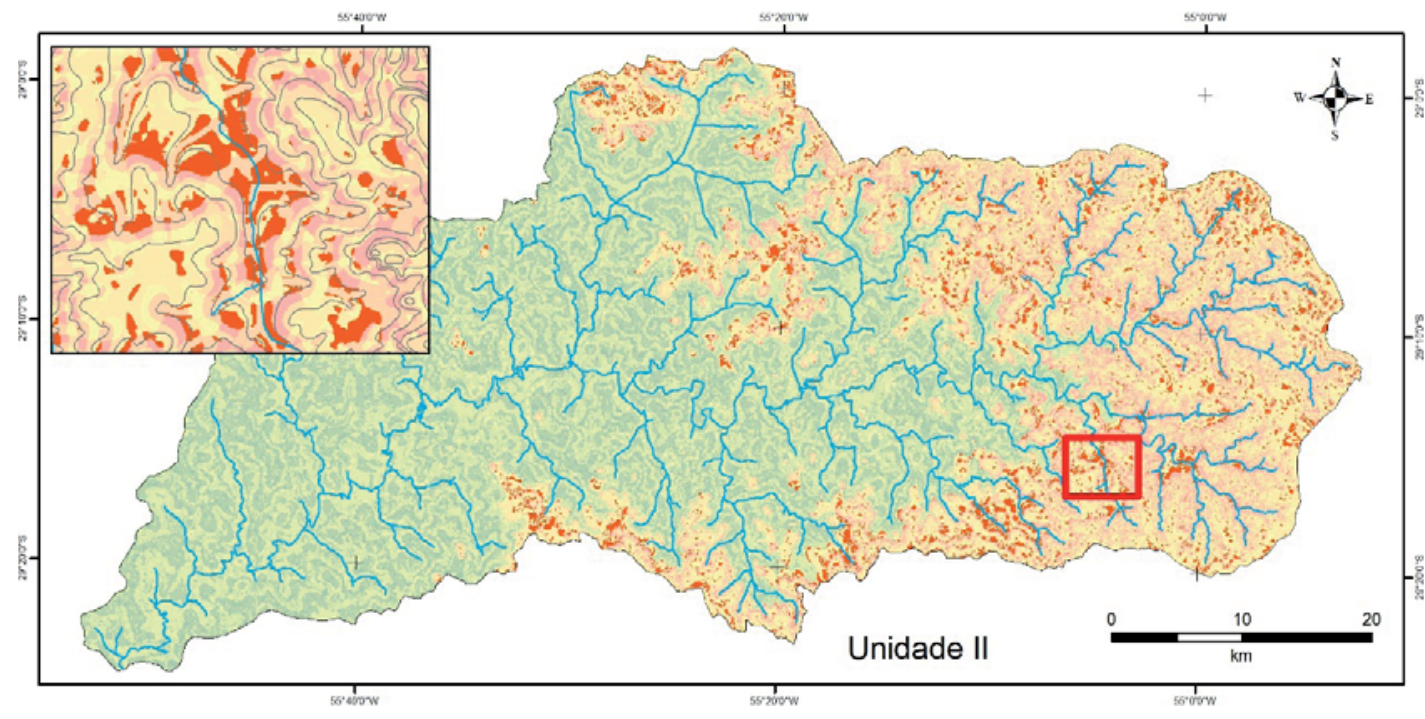

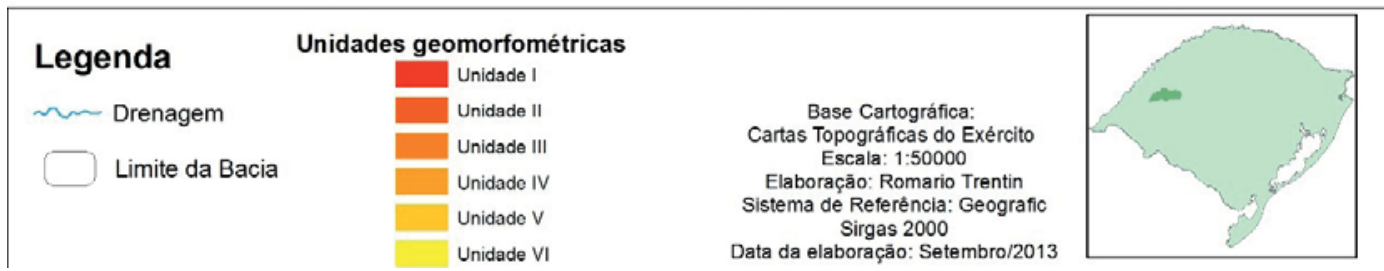

Figura 7 - Unidades geomorfométricas II.

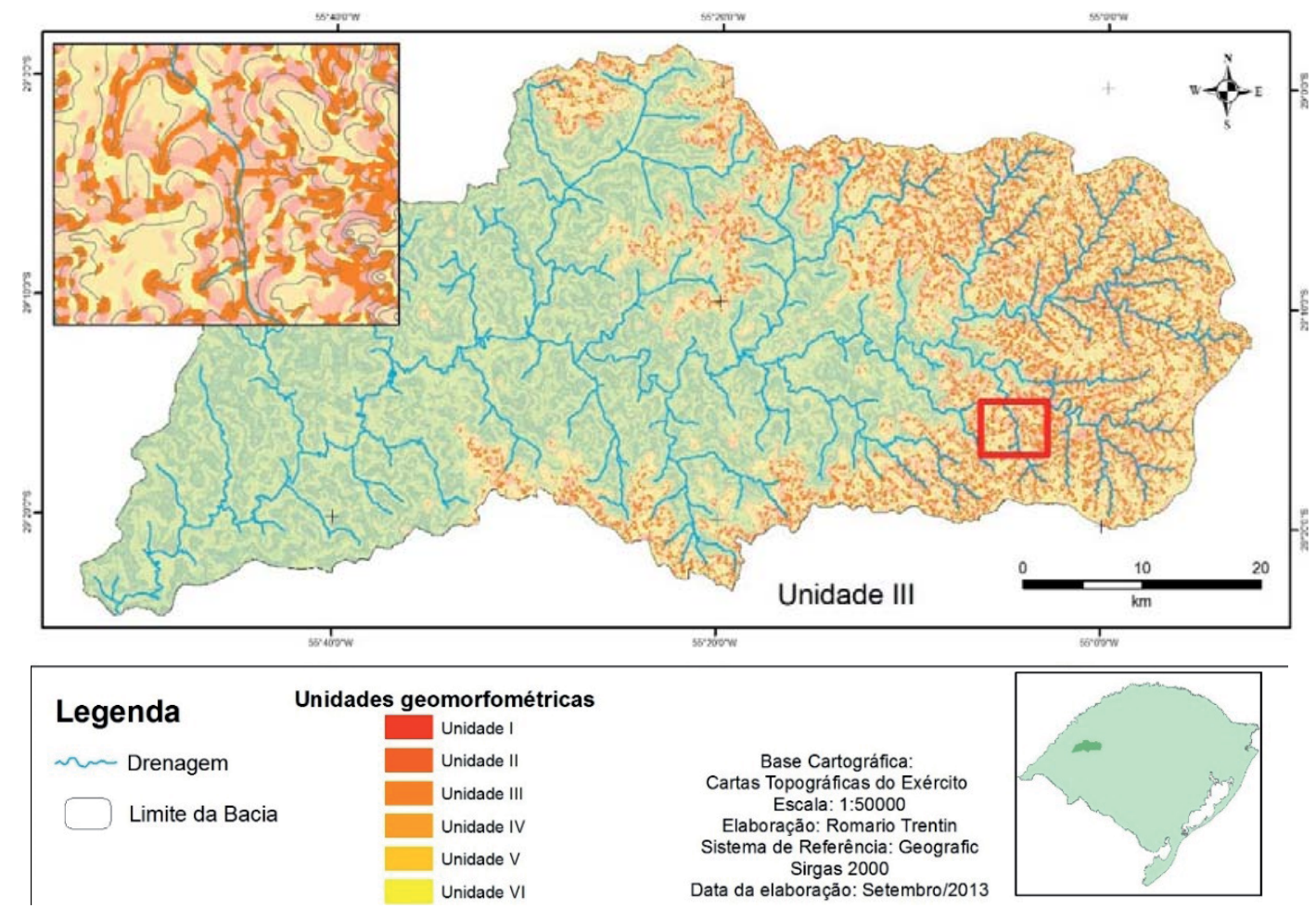

Figura 8 - Unidades geomorfométricas III.

Esta unidade representa o limite das áreas de colinas de rochas vulcânicas. Pelo substrato vulcânico ser predominantemente rochas vulcânicas e sua posição na vertente constituir o terço superior, caracteriza-se pelo afloramento rochoso, com solos rasos. 


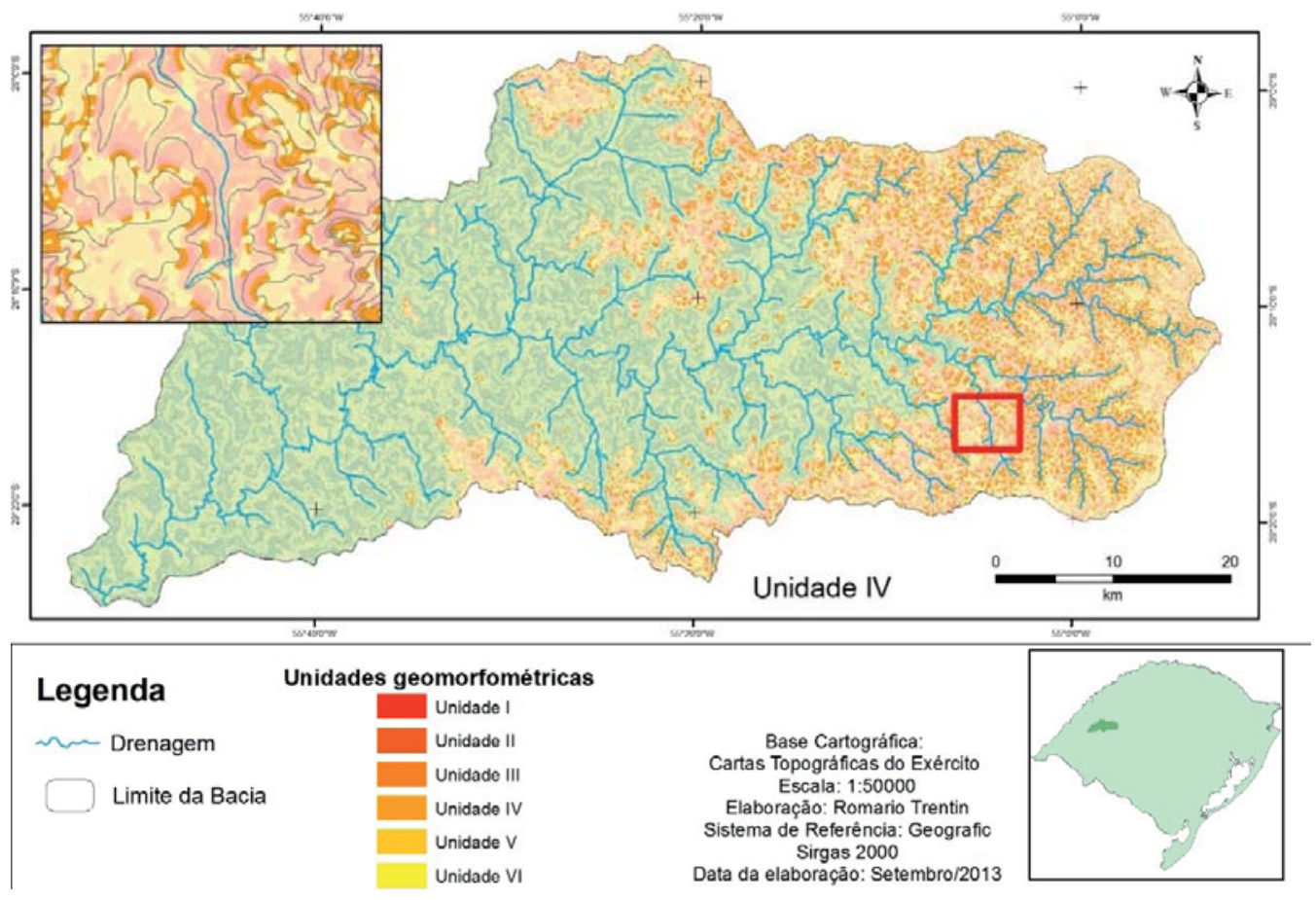

Figura 9 - Unidades geomorfométricas IV.

A unidade V (Figura 10), cobre aproximadamente 217ha, correspondendo a aproximadamente 7,5\% da área da bacia. Ocorre no alto curso da bacia formadas por áreas planas que constituem as áreas mais elevadas da bacia, espacialmente posicionada sobre os topos das vertentes.

Esta unidade relaciona-se geomorfologicamente às colinas de altitude, ou ainda, conforme Trentin et al. (2012), às colinas vulcânicas de topo plano, por estarem espacializadas sobre o substrato de rochas vulcânicas, nas porções de maiores altitudes da bacia hidrográfica, em porções aplainadas do relevo. Nestas áreas os solos são predominantemente rasos com afloramento de rochas.

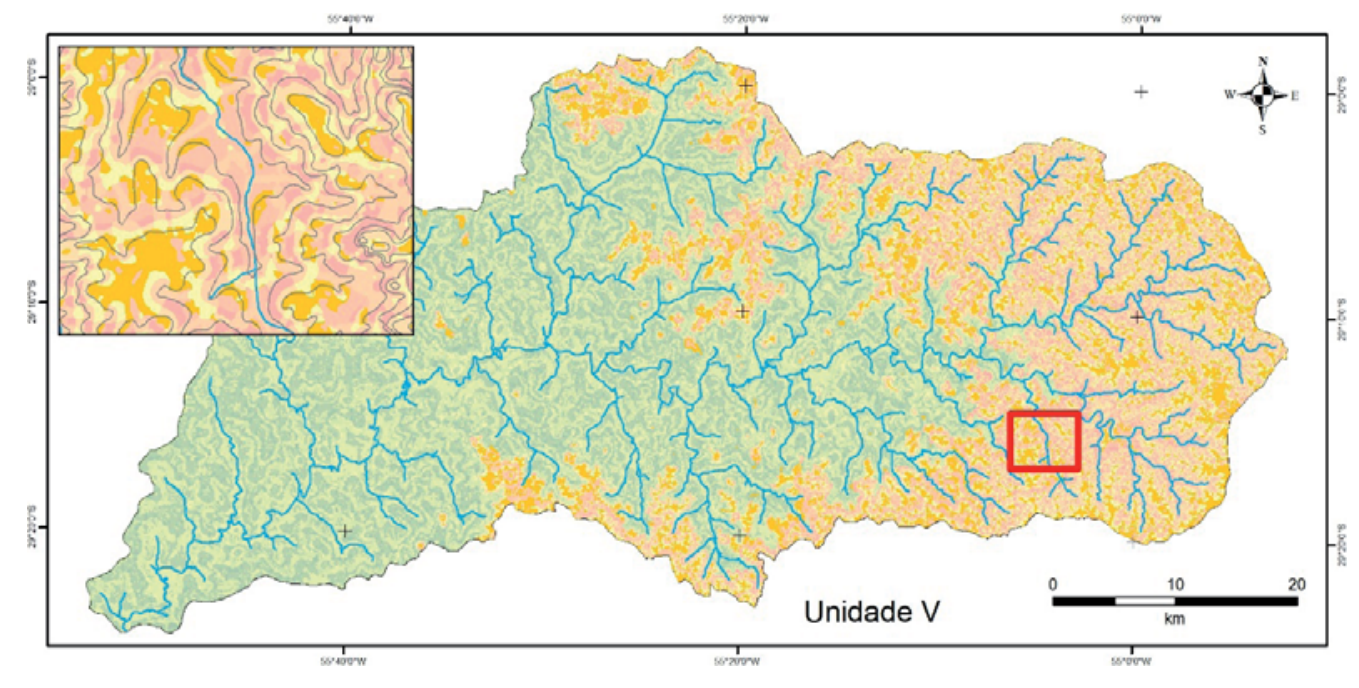

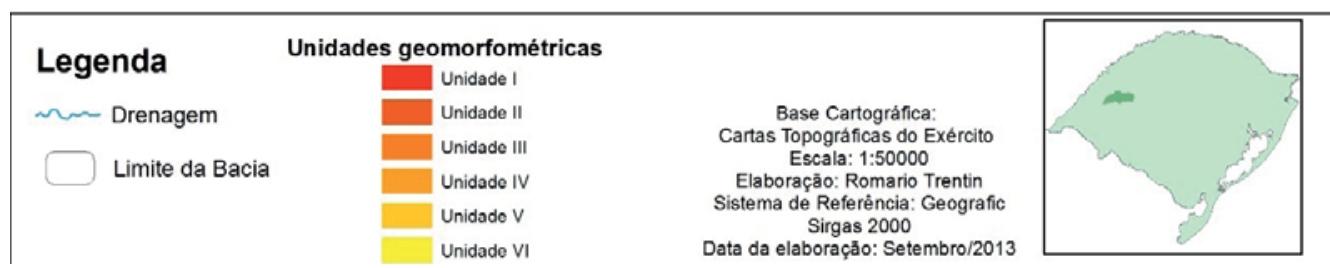

Figura 10 - Unidades geomorfométricas V. 
Trentin R. et al.

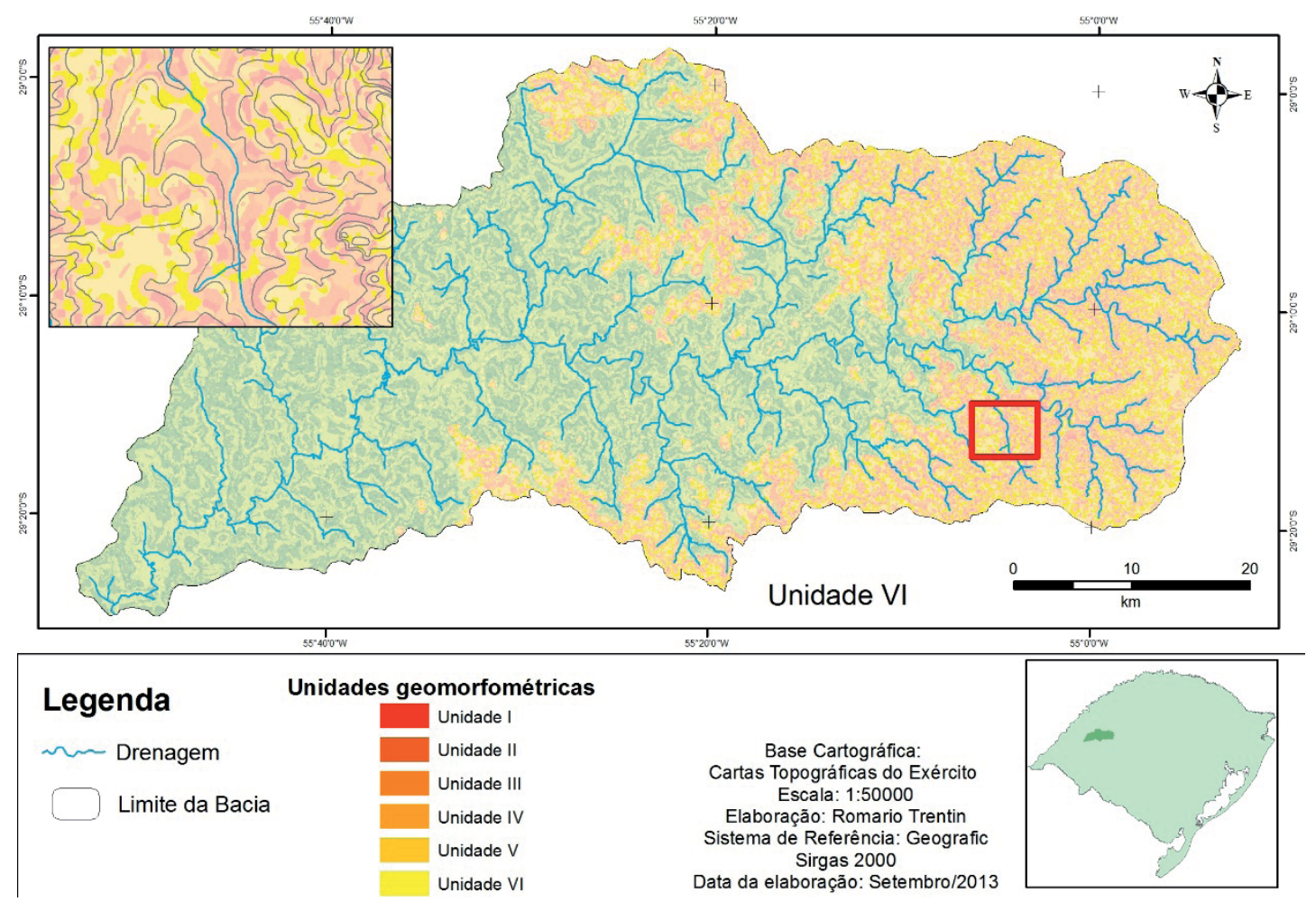

Figura 11 - Unidades geomorfométricas VI.

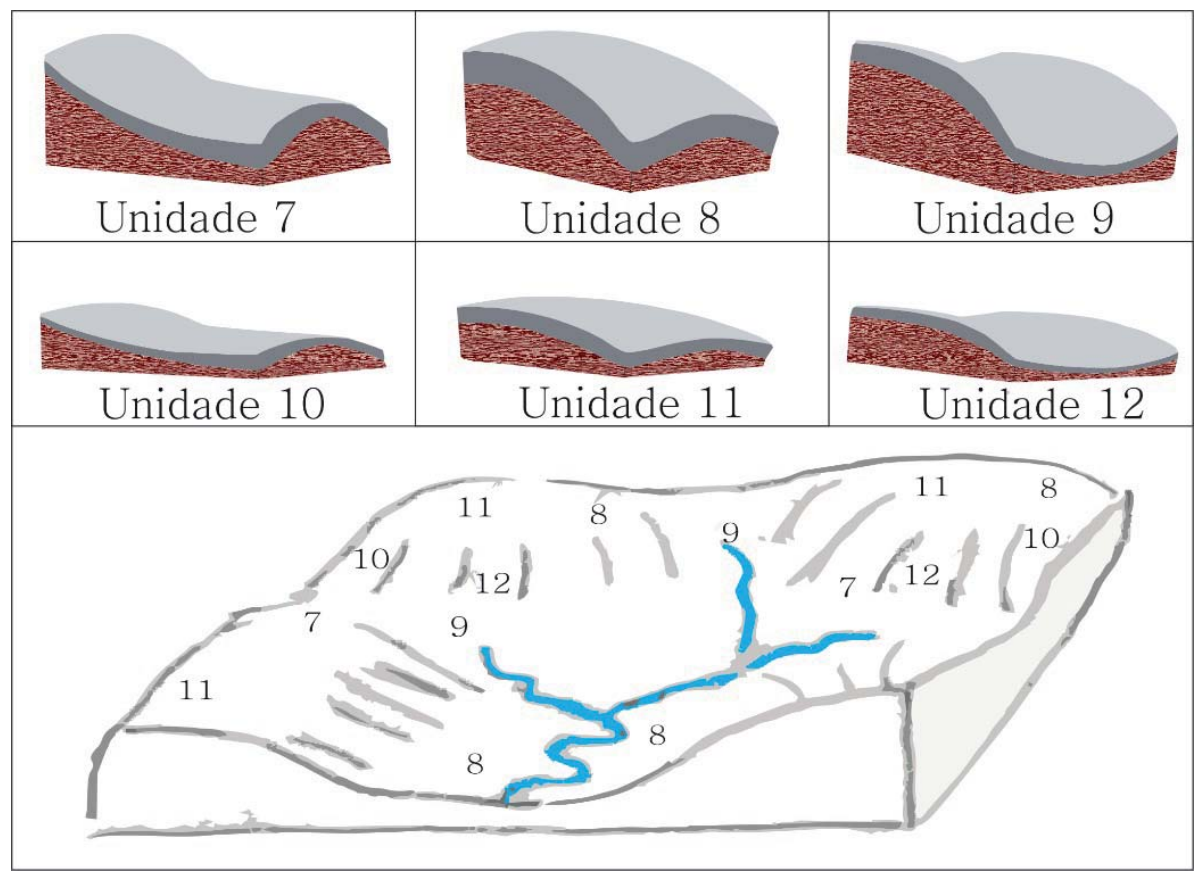

Figura 12 - Modelado e distribuição predominante das unidades VII a XII na bacia hidrográfica do Rio Itu.

A unidade VI (Figura 11), cobre aproximadamente 192ha, correspondendo a 6,5\% da área da bacia. Está caracterizada por áreas planas a montante da bacia (declividade inferiores a 5\% mas altitudes superiores a média), com predomínio da energia diminuindo e fluxo convergindo na vertente (perfil côncavo e plano convergente predominantemente). Espalhada por todo o alto curso são vertentes que marcam as porções superiores da unidade III.

Esta unidade além de ocupar as áreas de colinas 


\section{Compartimentação Geomorfométrica da Bacia Hidrográfica do Rio Itú/RS}

vulcânicas de topo plano, estende-se por vezes sobre as colinas de arenito. Nas áreas de maior altitude, ocorrem associadas à Unidade V, nos topos, porém esta ocupa geralmente áreas de surgência ou concentração de água, já nas áreas que ocorrem no médio curso da bacia hidrográfica esta unidade encontra-se sobre as colinas de arenito e, pelas características correspondem às áreas de acúmulo de areia, quando associado à ravinas e voçorocas, ou ainda às área de ocorrência dos areias, principalmente na porção ao norte, onde encontram-se os maiores areais, no arroio Puitã, afluente da margem direita da BHRI.

A figura 12 mostra o esquema da representação das unidades VII a XII, quanto ao modelado predominante das vertentes, bem como sua ocorrência e distribuição pela bacia hidrográfica do Rio Itu. As figuras 13, 14, 15, 16, 17 e 18 apresentam os mapas com as unidades VII à XII, respectivamente.
A unidade VII (figura 13) cobre 138ha, representando quase $5 \%$ do total da área da bacia. Está caracterizada por vertentes das áreas do médio e baixo curso com predomínio do médio curso da bacia hidrográfica (altitudes inferiores à média). Ocorre predominância de processos erosivo nas porções superiores da vertente (declividades superiores a 5\% e perfil côncavo) e de fluxo disperso (plano divergente). Espacialmente encontra-se nas porções de média vertente, por vezes próximas a drenagens.

Pelo grande espalhamento pela bacia hidrográfica, esta unidade estende-se por substratos de rocha vulcânicas, presentes nas porções de baixo curso, bem como sobre substratos de arenitos friáveis no médio curso (Formação Guará, conforme Trentin, 2011). Estas características lhes inferem processos associados à ravinas e voçorocas, principalmente quando em substrato arenítico.

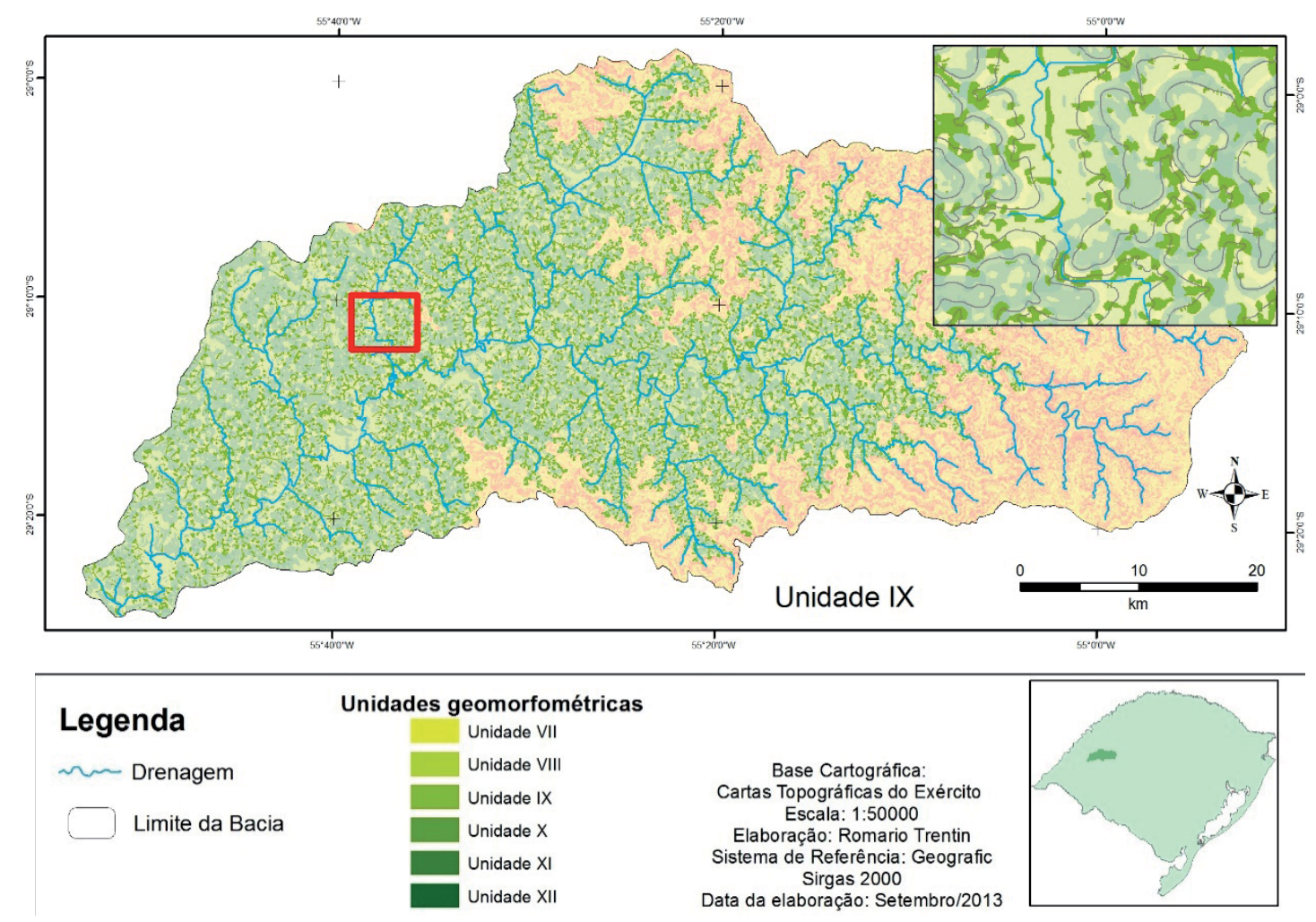

Figura 13 - Unidades geomorfométricas VII.

A unidade VIII (figura 14)cobre uma área de 447ha, próximo a 16\% da área da bacia. Representa vertentes das áreas de médio e baixo curso (altitudes inferiores à média), com a velocidade de fluxo aumentando em direção a base da vertente (perfil convexo), mas com fluxo divergente (plano divergente), o que pode gerar a formação de pequenos canais erosivos na base da vertente. Predominam nas áreas do terço inferior da vertente associadas as planícies de inundação.

Esta unidade estende-se por uma grande diversidade de substratos geológicos, por representar porções das vertentes. Geomorfologicamente, também 
apresenta diversidades, desde Morrotes de arenito até depósitos recentes. Quando associada às áreas de depósitos recentes, pelas condições morfométricas e velocidade de fluxo aumentada apresenta retrabalhamento destes depósitos.

A unidade IX (figura 15), cobre aproximadamente 395ha, sendo $14 \%$ do total da área da bacia. Localizada no médio/baixo curso da bacia hidrográfica (altitudes inferiores à média), com inclinações que favorecem a processo erosivos (declividades superiores a 5\%). Predominam vertentes que apresentam uma diminuição da energia do fluxo em direção a base, mas por ocorre uma convergência forma canais por erosão concentrada (perfil côncavo e plano convergente predominantemente). Ocorrem predominantemente na base das vertentes seguindo a rede de drenagem.

Esta unidade apresenta-se associado à grandes áreas junto aos cursos principais. Pelas condições morfométricas tendem a formar erosões lineares com transporte de sedimentos, sendo mais intensos sobre as colinas de arenitos nas porções de médio curso e menos intensas sobre as colinas de rocha vulcânicas do Baixo Platô da Campanha localizadas no baixo curso da bacia hidrográfica (TRENTIN et al., 2012).

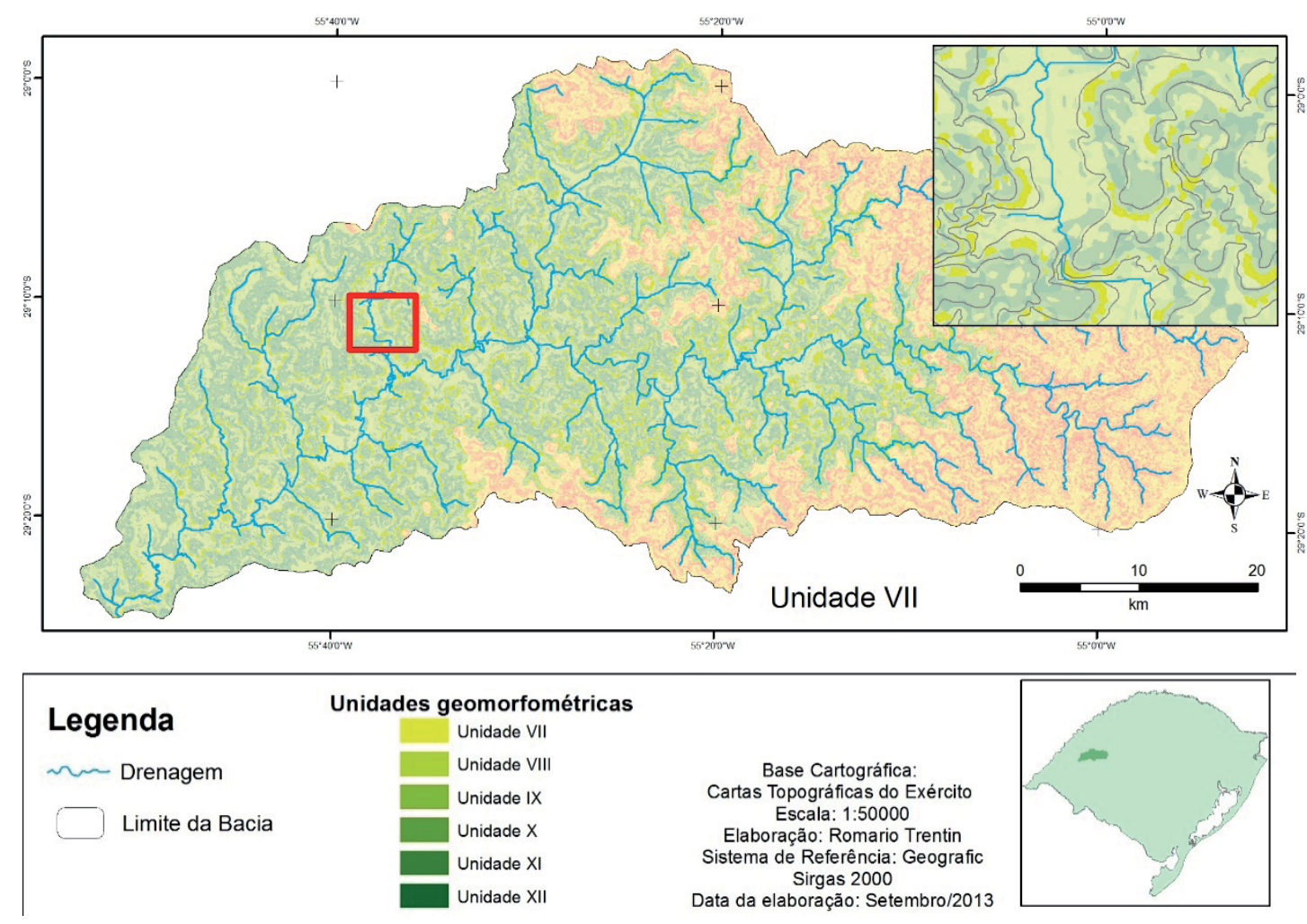

Figura 14 - Unidades geomorfométricas VIII.

A unidade X (figura 16), cobre aproximadamente 134ha, correspondendo a 5\% da área da bacia. Está caracterizada por áreas, principalmente no médio curso da bacia (altitudes inferiores à média), formadas por áreas planas (declividades inferiores a 5\%). Os processos variam do topo para a base dessa porção da vertente pela diminuição da energia do fluxo divergente (perfil côncavo e plano divergente). Formam, principalmente, na meia encosta em direção ao topo, ocupando o terço superior da vertente.
Esta unidade representa o limite entre as colinas onduladas do baixo e médio curso com ás áreas planas de topos. Ocupando o terço superior das vertentes, geralmente associam-se ainda às áreas de cornijas de arenito conforme Trentin at al., (2012).

A unidade XI (figura 17), cobre aproximadamente 410ha, correspondendo a aproximadamente $14,5 \%$ da área da bacia. Ocorre no médio e baixo curso da bacia hidrográfica, com predomínio no baixo curso, compondo as principais áreas planas da bacia nas porções de 


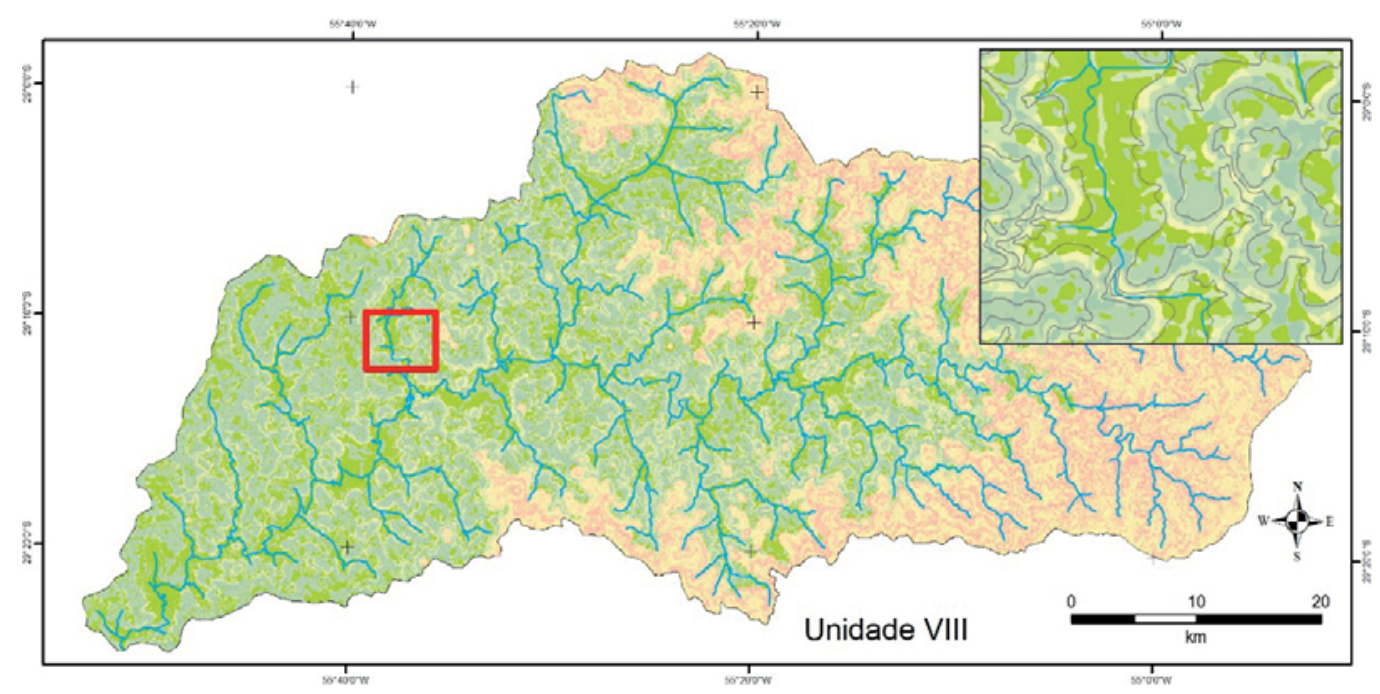

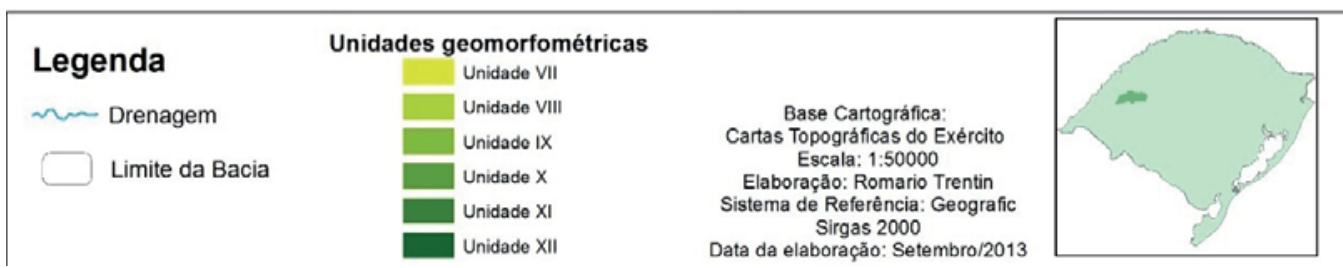

Figura 15 - Unidades geomorfométricas IX.
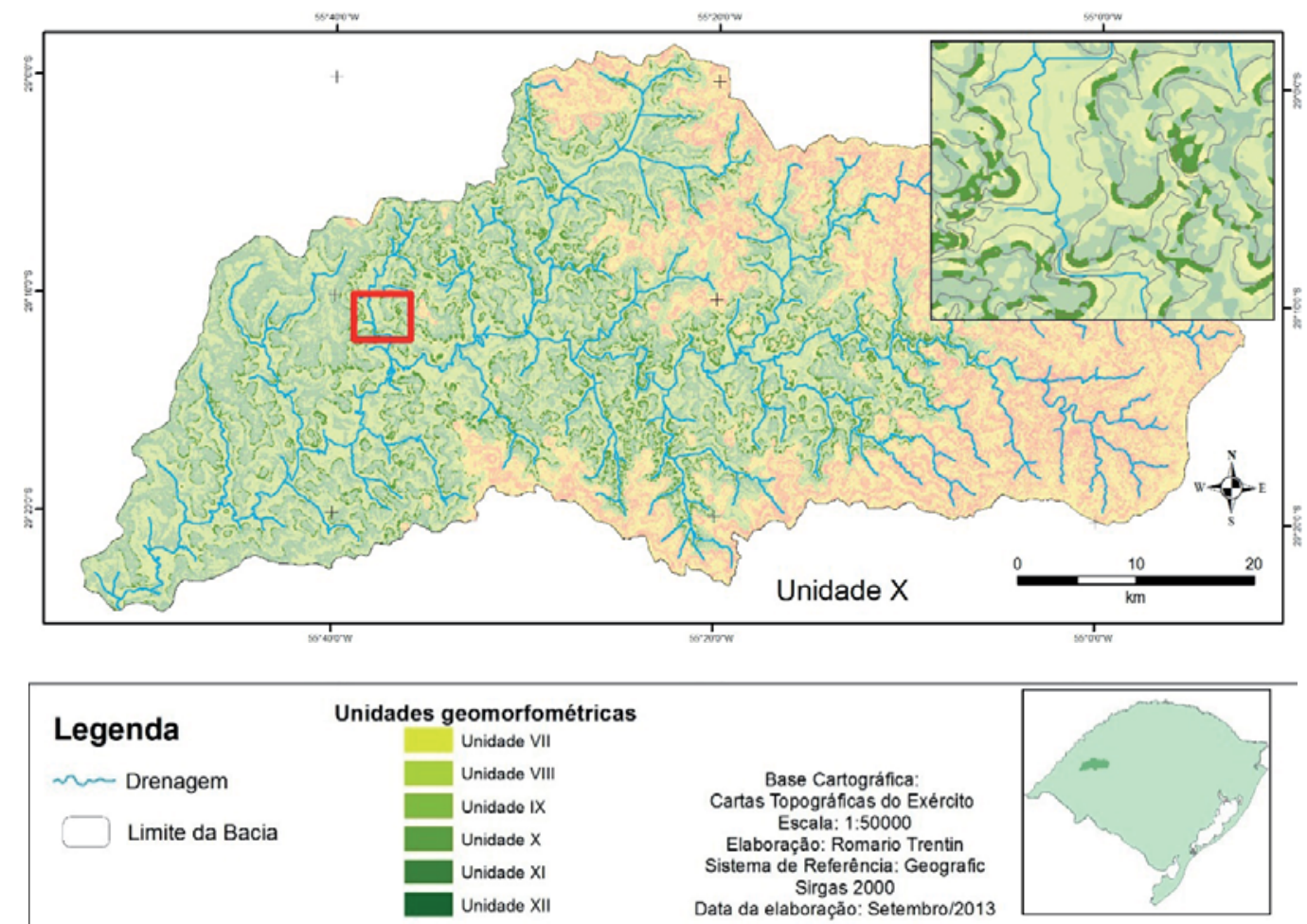

Figura 16 - Unidades geomorfométricas $X$.

divisores internos das sub-bacia. Os processos variam do topo para a base da vertente pelo aumento da energia do fluxo divergente (perfil convexo e plano divergente predominantemente). Formam amplas áreas no topo, correspondendo as áreas mais elevadas do baixo curso, junto ao divisores.

Apesar desta unidade estender-se pelo médio e baixo curso da BHRI, ocupando áreas de substrato vulcânico 
e arenítico, concentram-se predominante sobre rochas vulcânicas, constituindo ás colinas de rocha vulcânica sobre o Platô da Campanha (TRENTIN el al., 2012).

A unidade XII (figura 18), cobre aproximadamente 190ha, correspondendo a 6,5\% da área da bacia. Está caracterizada por áreas planas, com energia diminuindo e fluxo convergindo na base da vertente (declividade menor que 5\%, perfil côncavo e plano convergente predominantemente). Formam áreas próximas ao topo de vertentes entre os canais de drenagem, ocupando as porções de terço superior da vertente.

Esta unidade, associa-se as áreas de concentração de depósito de areia do topo em direção à base das vertentes por vezes associado aos afluentes dos canais principais, quando associados às rochas areníticas no médio curso da bacia e, às áreas de surgências de água nas porções de rocha vulcânica.

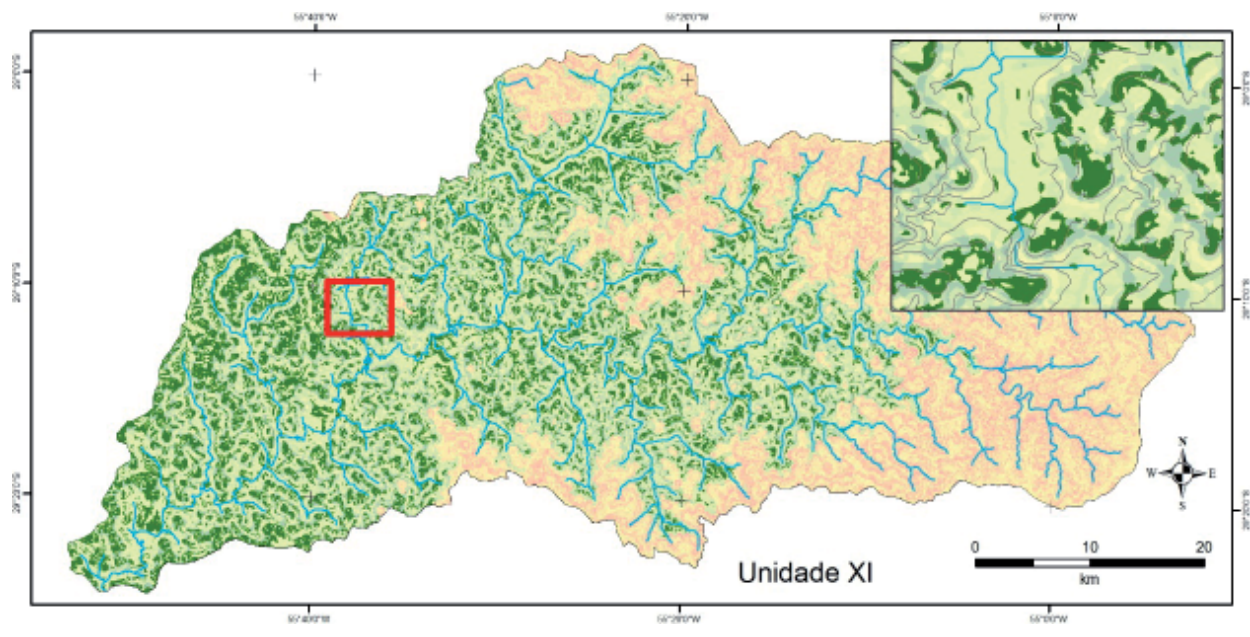

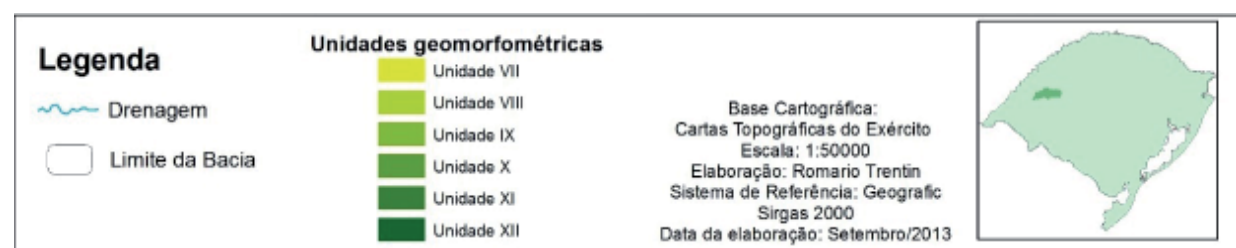

Figura 17 - Unidades geomorfométricas XI.

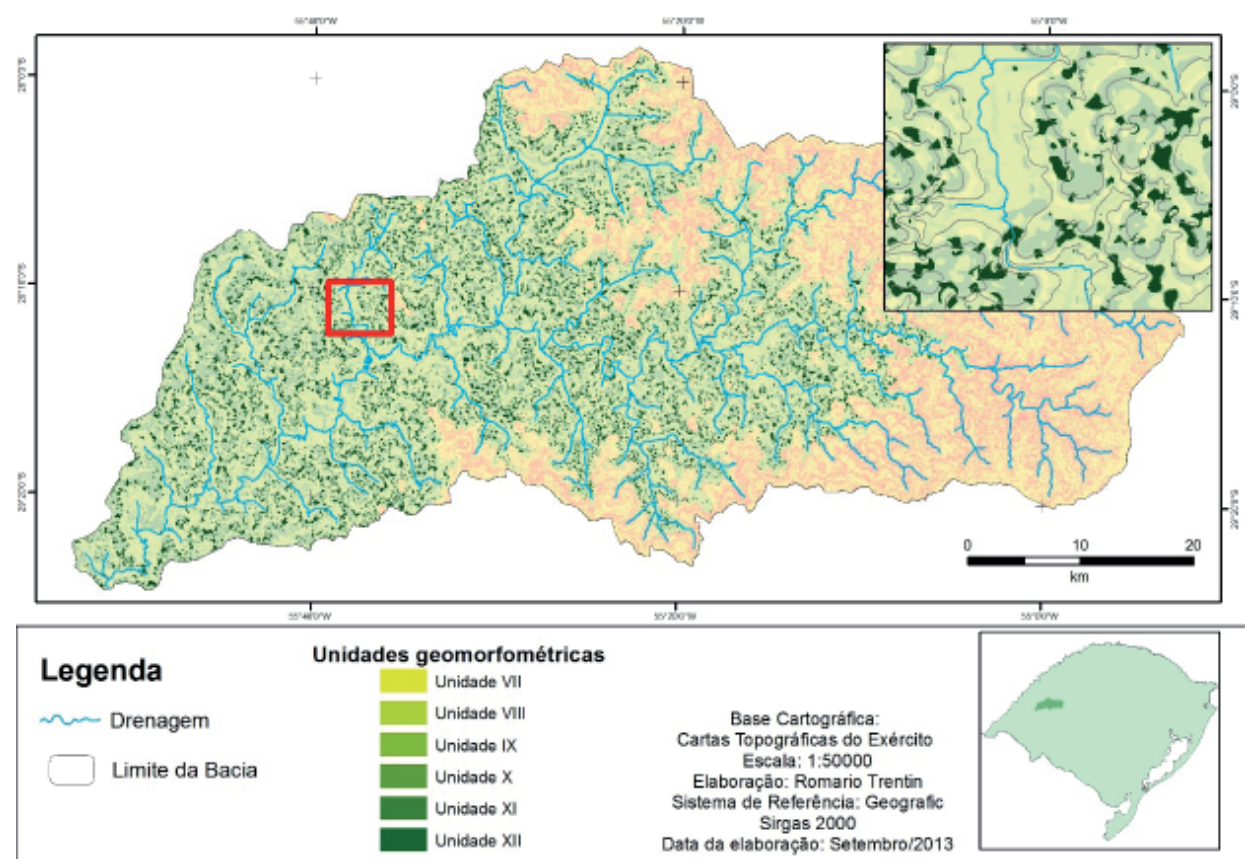

Figura 18 - Unidades geomorfométricas XII. 


\section{Compartimentação Geomorfométrica da Bacia Hidrográfica do Rio Itú/RS}

\section{Considerações Finais}

A partir do cruzamento das informações utilizando-se a árvore de decisão foram identificadas 24 unidades, que foram reagrupadas em 12 unidades mais representativas.

A utilização de MDE em geomorfologia permite o cálculo de variáveis associadas ao relevo com rapidez e precisão. O estabelecimento de critérios com parâmetros fixos para mapeamentos do relevo é importante para diminuir a subjetividade para a identificação e delimitação das feições geomorfológicas.

A observação dos mapas, por unidade, permitiu considerar que a metodologia utilizada é adequada para realizar caracterização das vertentes da área de estudo e a espacialização dos processos presentes, demonstrando grande potencial para suporte em trabalhos de compartimentação das formas do terreno.

Em se tratando de análise de parâmetros morfométricos relacionados à curvatura das vertentes, bem como inclinação e altitudes, o cruzamento destas variáveis apresenta como resultado unidades que representam porções das vertentes, permitindo análises e correlações frente à determinados processos. Por vezes estas unidades podem ser espacialmente correlacionadas com outras características do meio físico, como substrato geológico, compartimentos geomorfológicos, entre outros, porém, em outras situações, estas unidades não vão apresentar correlações espaciais, devendo ser identificados caso a caso, conforme objetivo específico de cada análise proposta.

\section{Referências Bibliográficas}

BISPO, P. C.; VALERIANO, M. M.; KUPLICH, T. M. Variáveis geomorfométricas locais e sua relação com a vegetação da região do interflúvio Madeira-Purus (AM-RO). Acta Amazonica, v. 39, n. 01, p-81-90, 2009.

CÁTEN A.; DALMOLIN, R. S. D.; RUIZ, L. F. C.; SEBEM, E.; PEREIRA, R. S. Pedometria aplicada à predição de classes de solos utilizando de regressões logísticas múltiplas. In: Simpósio Brasileiro de Sensoriamento Remoto, XIV, 2009, Natal. Anais... Natal: INPE, p. 25-30, 2009.

CHRISTOFOLETTI, A. Geomorfologia Fluvial. São Paulo: Edgard Blücher, 1980. 313 p.

DIKAU, R. The application of a digital relief model to landform analysis in geomorphology. In: RAPER, J. (Ed.). Three- dimensional applications in geographic information systems. New York: Taylor and Francis, p.51-77, 1989.

FRANKLIN, S. E., and D. Peddle, 1987, Texture analysis of digital image data using spatial cooccurrence, Computers \& Geosciences. 13(3): 293-311.

GALLANT, J. C.; WILSON, J. P. Primary topographic attributes. In: WILSON, J. P.; GALLANT, J. C. (Eds.). Terrain Analysis: Principles and applications. New York: John Wiley, p.51-85, 2000.

GUERRA, A. J. T. e CUNHA, S. B. da. A questão ambiental Diferentes abordagens. Rio de Janeiro: Ed. Bertrand Brasil, 2003.

GUERRA, A. J. T. e CUNHA, S. B. da. Geomorfologia Exercícios, Técnicas e Aplicações. Rio de Janeiro: Ed. Bertrand Brasil, 1996.

GUERRA, A. T. e GUERRA, A. J. T. Novo dicionário geológicogeomorfológico. 5 ed. Rio de Janeiro: Bertrand Brasil, 2005.

HAMMOND, E.H. Analysis of properties in landform geography: an application to broad-scale landform mapping. Ann. Assoc. Am. Geogr. 54, 11-19, 1954.

HORN, B. K. P. Hill shading and the reflectance map. Proceedings of the IEEE, n. 69, v. 01, p. 14-47, 1981.

HUGGET, R. J. Soil Landscape Systems: A model of soil genesis. Geoderma, v.13, p.01-22, 1975.

HUTCHINSON, M. F. A new procedure for gridding elevation and stream line data with automatic removal of spurious pits. Journal of Hydrology, 106, 211-232, 1989.

HUTCHINSON, M. F. A. A locally adaptive approach to the interpolation of digital elevation models. In: International Conference/Workshop on Integrating GIS and Environmental Modeling, National Center for Geographic Information and Analysis. 3. 1996, Santa Bárbara. Proceedings... Santa Bárbara: University of California, 1996. CD-RON.

HUTCHINSON, M. F. A. Adding the Z dimension. In: WILSON, J. P.; FOTHERINGHAM, A.S. The handbook of geographic information science. 1. ed. Blackwell Publishing Ltd. 2008. p. $144-168$.

IPPOLITI, G. A.; COSTA, L.M.; SCHAEFER, C. E.G. R.; FERNANDES FILHO, E. I.; GAGGERO, M. R.; SOUZA, E. Análise digital do terreno: ferramenta na identificação de pedoformas em microbacias na região de “Mar de Morros” (MG). Revista Brasileira de Ciência do Solo, v.29, p.269-276, 2005.

IWAHASHI, J.; PIKE, R. J. Automated classifications of topography from DEMs by an unsupervised nested- 
means algorithm and a three-part geometric signature. Geomorphology 86 (3-4): 409-440, 2007.

MENDIONDO, E. M.; COLLISCHONN, W.; BULHÕES MENDES, C. A. Modelos numéricos do terreno e suas aplicações a bacias hidrográficas 2: Obtenção de atributos. In: XVII Congreso Nacional del Agua / II Simposio de Recursos Hídricos del Cono Sur. Anais...1998.

MESCERJAKOV, J. P. Les concepts de mophostructure et de morphosculpture: un nouvel instrument de l'analyse géomorphologique. Annales de Geographie, n. 423, v. 77, set./ out. 1968, p. 539-552.

MOORE, I. D.; GESSLER, G.A.; PETERSON, G.A. Soil attribute prediction using terrain analysis. Soil Science Society of America Journal, v.57, p.443-452, 1993.

MOORE, I. D., GRAYSON, R. B., LADSON, A. R. Digital terrain modeling: A review of Hydrological, geomorphological an biological applications. Hydrological Processes, v. 5, p. 3-30, 1991.

MUÑOZ, V. A. Análise geomorfométrica de dados SRTM aplicada ao estudo das relações solo-relevo. Instituto Nacional de Pesquisas Espaciais, São José dos Campos, 2009. 112p. (INPE-15796-TDI/1531). Dissertação (Mestrado em Sensoriamento Remoto). - Instituto Nacional de Pesquisas Espaciais.

PENCK, W. Morphological Analysis of Landforms. Londres: McMillan, 1953.

PENNOCK, D. J. Terrain attributes, landform segmentation, and soil redistribution. Soil and Tillage Research 69 (1-2), 15-26, 2003.

PIKE, R.J.; EVANS, I., HENGL, T. Geomorphometry: A Brief Guide. In: Geomorphometry - Concepts, Software, Applications, Hengl, T. and Hannes I. Reuter (eds.), Series Developments in Soil Science vol. 33, Elsevier, pp. 3-30, 2008.

PROJETO RADAMBRASIL. Folha SH. 22 Porto Alegre e parte das folhas SH. 21 Uruguaiana e SI. 22 Lagoa Mirim. Rio de Janeiro, Instituto Brasileiro de Geografia e Estatística, 796 . 1986.

ROBAINA, L.E.S. Compartimentação Geomorfológica da Bacia Hidrográfica do Ibicuí, Rio Grande do Sul, Brasil: Proposta de Classificação. Revista Brasileira de Geomorfologia. v.11 n.2, 2010. p. $11-23$.

ROSS. J. L.S. (Org). Geografia do Brasil. São Paulo: EDUSP, 1995. $546 \mathrm{p}$.
ROSS. J. L.S. Geomorfologia. Ambiente e Planejamento. São Paulo: Contexto,1990.

RUIZ, R. S. R; CAMPOS VELHO, H.F.; SANTOS, R. D. C.; TREVISAN, M. Árvores de Decisão na Classificação de Dados Astronômicos. Trends in Applied and Computational Mathematics. Vol 10, No 1, p. 164-169. 2009

SANTOS, R. F. dos. Planejamento Ambiental: teoria e prática. São Paulo: Oficina de Textos, 2004.

SCHMIDT, J., DIKAU, R. Extracting geomorphometric attributes and objects from digital elevation models semantics, methods, future needs. In: Dikau, R., Saurer, H. (Eds.), GIS for Earth Surface Systems — Analysis and Modelling of the Natural Environment. Schweizbart'sche Verlagsbuchhandlung, pp. 153-173, 1999.

SHARY, P.A., SHARAYA, L.S., MITUSOV, A.V. Fundamental quantitative methods of land surface analysis. Geoderma 107 (1-2), 1-32, 2002.

SILVEIRA, C.T; FIORI, A.P.; SCHILIPACK, P.; DIAS, S.M. Mapeamento preliminar da suscetibilidade natural a movimentos de massa da Serra do Mar Paranaense apoiado na análise digital do relevo. Revista Brasileira de Geomorfologia, v. 15, n. 01, p. 3-22, 2014b.

SILVEIRA, R.M.P.; SILVEIRA, C.T., OKA-FIORI, C. Emprego de técnicas de inferência espacial para identificação de unidades de relevo apoiado em atributos topográficos e árvore de decisão. Revista Brasileira de Geomorfologia, v. 15, n. 01, p. 87-101, 2014a.

SIRTOLI, A. E.; SILVEIRA, C. T.; MONTOVANI, L. E.; SIRTOLI, A. R. A.; OKA-FIORI, C. Atributos do relevo derivados de modelo digital de elevação e suas relações com solos. Scientia agraria, v.9, n.3, p.317-329, 2008.

SPEIGHT, J.G. Parametric description of landform. In: Stewart, G.A. (Ed.), Land Evaluation: Papers of a CSIRO Symposium. Macmillan, Melbourne, pp. 239-250, 1968.

TRENTIN, R. Mapeamento geomorfológico e caracterização geoambiental da bacia hidrográfica do rio Itu - oeste do Rio Grande do Sul - Brasil. 2011. 215 f. Tese de Doutorado PPGGeografia/UFPR, Curitiba. 2011.

TRENTIN, R. SANTOS, L. C. ROBAinA, L. E. S. Compartimentação geomorfológica da bacia hidrográfica do rio Itu - Oeste do Rio Grande do Sul - Brasil. Revista Sociedade \& Natureza, Uberlândia, v.24, n.1, p. 127-142, 2012

TROPPMAIR, H. Geomorfologia e Ecologia. Boletim de Geografia Teorética, Rio Claro - SP, 20 (39), p. 32-43, 1990. 
VALERIANO, M. M. Curvatura vertical de vertentes em microbacias pela análise de modelos digitais de elevação. Revista Brasileira de Engenharia Agrícola e Ambiental, Campina Grande, v.7, n.3, p.539-546, 2003.

VELOSO, A. A importância do estudo das vertentes. Geographia, v. 4, n. 8, p 1-5, 2002.

WILSON, J. P.; GALLANT, J. C. Digital terrain analysis, chapter 1. In: WILSON, J. P.; GALLANT, J. C. (Eds.). Terrain analysis: principles and applications. New York: John Wiley \& Sons, p.1-27, 2000.
WOOD, J. The geomorphological characterisation of digital elevation models. Leicester, UK, 1996. 185p. PhD Thesis University of Leicester. Disponível em: http://www.soi.city. ac.uk/ jwo/phd.

XAVIER DA SILVA, J. Geomorfologia e Geoprocessamento. In: GUERRA, A. J. T.; CUNHA, S. B. da. Geomorfologia uma atualização de bases e conceitos. Rio de Janeiro: Bertrand Brasil, 2005.

ZEVENBERGEN, L.W.; THORNE, C.R. Quantitative Analysis of Land Surface Topography. Earth Surface Processes and Landforms, v.12, p.47-56, 1987. 